\title{
Assessment of an Average Controller for a DC/DC Converter via Either a PWM or a Sigma-Delta-Modulator
}

\author{
R. Silva-Ortigoza, ${ }^{1}$ F. Carrizosa-Corral, ${ }^{2}$ J. J. Gálvez-Gamboa, ${ }^{2}$ \\ M. Marcelino-Aranda, ${ }^{3}$ D. Muñoz-Carrillo, ${ }^{4}$ and H. Taud ${ }^{1}$ \\ ${ }^{1}$ Instituto Politécnico Nacional, CIDETEC, Área de Mecatrónica, Unidad Profesional Adolfo López Mateos, 07700 México, DF, Mexico \\ ${ }^{2}$ Instituto Tecnológico de Culiacán, Departamento de Metal-Mecánica, 80220 Culiacán, SIN, Mexico \\ ${ }^{3}$ Instituto Politécnico Nacional, UPIICSA, Sección de Estudios de Posgrado e Investigación, 08400 México, DF, Mexico \\ ${ }^{4}$ CINVESTAV-IPN, Departamento de Control Automático, 07360 México, DF, Mexico
}

Correspondence should be addressed to R. Silva-Ortigoza; rsilvao@ipn.mx

Received 27 May 2014; Revised 16 September 2014; Accepted 17 September 2014; Published 26 November 2014

Academic Editor: Hamid R. Karimi

Copyright (C) 2014 R. Silva-Ortigoza et al. This is an open access article distributed under the Creative Commons Attribution License, which permits unrestricted use, distribution, and reproduction in any medium, provided the original work is properly cited.

\begin{abstract}
Sliding mode control is a discontinuous control technique that is, by its nature, appropriate for controlling variable structure systems, such as the switch regulated systems employed in power electronics. However, when designing control laws based on the average models of these systems a modulator is necessary for their experimental implementation. Among the most widely used modulators in power electronics are the pulse width modulation (PWM) and, more recently, the sigma-delta-modulator $(\Sigma-\Delta$ modulator). Based on the importance of achieving an appropriate implementation of average control laws and the relevance of the trajectory tracking task in DC/DC power converters, for the first time, this research presents the assessment of the experimental results obtained when one of these controllers is implemented through either a PWM or a $\Sigma$ - $\Delta$-modulator to perform such a task. A comparative assessment based on the integral square error (ISE) index shows that, at frequencies with similar efficiency, the $\Sigma$ - $\Delta$-modulator provides a better tracking performance for the DC/DC Buck converter. In this paper, an average control based on differential flatness was used to perform the experiments. It is worth mentioning that a different trajectory tracking controller could have been selected for this research.
\end{abstract}

\section{Introduction}

Sliding mode control is a well-known discontinuous feedback control technique which has been exhaustively explored in many books and journal articles by various authors. The technique is naturally suited for controlling variable structure systems. A complete account of the history and fundamental results of sliding modes is found in books, such as those presented by Emelyanov [1], Utkin [2, 3], and Utkin et al. [4]. A book with a terse and very clear exposition of these topics along with some interesting laboratory and industrial applications is the one introduced by Edwards and Spurgeon [5]. Also, well-documented books that contain chapters on sliding mode control are those of Slotine and Li [6], Sastry [7], Kwatny and Blankenship [8], and Żak [9], among others. Furthermore, the state of the art about sliding modes has been summarized in the edited books by Young and Özgüner [10], Perruquetti and Barbot [11], Sabanovic et al. [12], and recently by Fridman et al. [13]. More recently, other interesting works about applications of sliding modes are those presented in [14-16] and the references therein. Likewise, works associated with vehicle suspension systems have been developed by $\mathrm{Li}$ et al. in [17-19] and the references therein. Moreover, applications to DC/DC power converter-DC motor systems have been reported in [20,21].

In the aforementioned literature, several applications of sliding modes have been introduced. However, it is often necessary to design control laws based on the average models of switched systems. When designing control laws based on such models, particularly DC/DC power converters, a modulator is required for their experimental implementation. Thus, based on $[22,23]$, this work focuses on the experimental 
assessment of a PWM and a $\Sigma$ - $\Delta$-modulator, when an average controller performs the trajectory tracking task in a DC/DC converter.

Nowadays modulators have a wide variety of applications which include, among others, communications, audio, power delivery, and voltage regulation. In particular, this research is focused on their application to the proper handling of the switches associated with DC/DC power converters. Among the most popular modulators used in power electronics, the most prominent are the pulse width modulation (PWM) and, more recently, the sigma-delta-modulator ( $\Sigma-\Delta$-modulator). These modulators allow the switched implementation of any feedback controller that has been synthesized from an average viewpoint [24]. A complete account of $\sum$ - $\Delta$-modulators, extensively used in analog signal encoding, is found in the classic book by Steele [25] and in the excellent book edited by Norsworthy et al. [26]. Different research works have addressed the problem of appropriately implementing average control laws in DC/DC power converters, via a PWM or a $\Sigma$ - $\Delta$-modulator.

On the one hand, the PWM has been extensively used for switching DC/DC power converters. For the regulation of the Buck power converter output voltage, the study in [27] presents a comparison between two proportional-integralderivative (PID) average controllers implemented through a PWM. Analysis and simulation results are verified by setting up one of the controllers on a field programming gate array (FPGA) platform. Likewise, in [28] an experimental comparison of the generalized proportional integral (GPI) and the PID average controllers to stabilize the output voltage of a Buck converter is performed. Both controllers are implemented through a PWM using a FPGA. Furthermore, applications regarding the angular velocity trajectory tracking task in DC/DC power converter driven DC motor systems have been reported in [29-34]. Linares-Flores in [29] and Antritter et al. in [30], treating the angular velocity trajectory tracking task in a Buck converter-DC motor system, presented an average differential flatness-based controller. In both works, the experimental implementation of such a controller was achieved via a PWM and a data acquisition card. For this same system, El Fadil and Giri in [31] elaborated an average controller via the backstepping approach for both nonadaptive and adaptive versions. They show, through numerical simulations that included a PWM, that the adaptive version performs better against uncertain load changes. In the work of Linares-Flores et al. [32], an exact tracking error dynamics passive output feedback (ETEDPOF) controller for a Buck-Boost-converter driven DC motor is introduced. The designed continuous feedback control law is implemented by means of a PWM. Experimental results were obtained using an acquisition card. Recently, Linares-Flores et al. in [33] presented the use of the ETEDPOF methodology, experimentally implemented through a PWM, for the load torque estimation in a DC/DC Boost converter-DC motor system. More recently, an average control based on differential flatness for a DC/DC Buck converter-DC motor system that carries out the angular velocity trajectory tracking task was reported by Silva-Ortigoza et al. in [34]. The switched implementation of the control was accomplished by means of PWM, showing good performance and robustness against parametric uncertainties. Further applications of switched implementations of average controllers through a PWM can be found in [35-39].

On the other hand, switched implementation of average controllers for power converters via the $\Sigma-\Delta$-modulator has been presented in $[22,23,40,41]$. Thus, a $\Sigma$ - $\Delta$-modulator is used by Capponi et al. in [40] to achieve the implementation of a PID controller in a DC/DC Buck converter prototype via a FPGA. In [22], it is shown that a $\Sigma$ - $\Delta$-modulator can be used to translate an average dynamic output feedback controller into a discontinuous one with the property that the "equivalent output" signal of the modulator, in an ideal sliding mode sense, precisely matches the modulator's input signal generated by the continuous output feedback controller. The proposal points to a systematic approach to controllers design of switched systems based on average designs. The results there reported are directly applied to the implementation, via simulations, of a continuous passivity based controller for a Boost converter. Sira-Ramírez and Silva-Ortigoza [23] presented experimental applications of the implementation of some average controllers via a $\Sigma-\Delta$-modulator in different DC/DC power converters. An average linear-time-varying state feedback control for the DC/DC Buck-Buck converter was proposed in [41], based on ETEDPOF. In that work, the simulations included controller implementation through a $\Sigma$ - $\Delta$-modulator to generate the switched signals. Another important contribution has been recently provided by SiraRamírez et al. in [42], where they proposed an inputoutput based feedback controller for the sliding mode control of linear controllable switched systems. The closed loop system was led towards a robust sliding mode behavior on a state naturally represented by a $\Sigma-\Delta$-modulator. Their theoretical findings were applied experimentally to solve the trajectory tracking task in a DC/DC Buck power converter. Moreover, applications of average controllers implementation via a $\Sigma$ - $\Delta$-modulator in DC/DC power converter-DC motor systems have been studied in [43-46]. In [43], there was presented an average smooth starter, based on differential flatness, for the velocity regulation of a DC motor powered via a DC/DC Buck converter. Also, for the DC/DC Buck converter-DC motor combination in [44], a GPI average control law was introduced using the flatness of the combined system for the angular velocity trajectory tracking task. Likewise, for this same combination and task, the design of a dynamic output feedback controller via the energy shaping and damping injection method was described in [45]. In the works of Linares-Flores and Sira-Ramírez [43-45], the effectiveness of the proposed controllers was verified by computer simulations. Recently, Silva-Ortigoza et al. [46] have presented a two-stage control based on differential flatness for the speed control without velocity measurements of a DC/DC Buck converter-DC motor system. It has been shown via realistic simulations that the proposed control scheme effectively provides robustness to the tracking performance in the presence of uncertainties associated with the system parameters. Finally, further applications of average controllers implemented via $\Sigma$ - $\Delta$-modulator are found in $[47,48]$. 
The literature provided herein shows that both modulators, PWM and $\Sigma$ - $\Delta$-modulator, are important when implementing average control laws and that they can be employed in the same power converter applications. In order to select the most suitable for each application, one needs to evaluate the different advantages provided to power converters by these modulators. Different approaches for comparing both modulator configurations have been developed in [49-52]. A comparison of these modulators for an AC/DC Boost converter was presented in [49], focusing on both the power factor correction action and the spectrum of the conducted emission. In [50] the rms noise power in a DC/DC power converter is experimentally compared when using either a PWM or a $\Sigma$ - $\Delta$-modulator and a multibit $\Sigma-\Delta$-modulator is simulated, and this multibit modulator provided a significant reduction in the spectral output of the DC/DC power converter. Hirota et al. [51] compared the use of a $\Sigma-\Delta$-modulator versus a PWM in an AC/AC converter and focused on the reduction in high frequency noise peaks of the output voltage. Finally, the work reported by Orcioni et al. in [52] proposed a $\Sigma$ - $\Delta$-modulator for handling the switches of a DC/AC power converter, presenting the advantage, in comparison with a PWM implementation, of reducing the conducted electromagnetic interferences.

Until now, none of the publications that compare the PWM with the $\Sigma$ - $\Delta$-modulator have addressed the trajectory tracking task in DC/DC power converters, which is a current and relevant research topic. Therefore, the objective of this research is to establish which of these modulators is more suitable for performing such a task in a DC/DC converter. To this end, a DC/DC Buck power converter and a flatness-based tracking controller are used. Furthermore, the corresponding experimental results are included.

This paper is structured as follows. Section 2 presents the converter mathematical model, the average controller, and its implementation through the modulators. Details on the experimental setup are described in Section 3. The experimental results are shown and analyzed in Section 4. Section 5 is devoted to the conclusions and future research. Finally, in the Appendix some of the $\Sigma$ - $\Delta$-modulator's main features are described.

\section{Flatness-Based Control via Modulators for the DC/DC Buck Converter}

This section presents a general description of the DC/DC Buck switching converter and its average model associated with the continuous conduction mode. Then, following the differential flatness approach provided in [53], an average trajectory tracking controller is designed based on this model. In order to use this controller, the implementation is made through PWM and $\Sigma$ - $\Delta$-modulator, which connects the controller to the DC/DC Buck converter as described at the end of this section.

2.1. DC/DC Buck Converter Model. The DC/DC Buck power converter, shown in Figure 1(a), includes a power supply, an inductor, a capacitor, a resistive load, a diode, and a transistor.

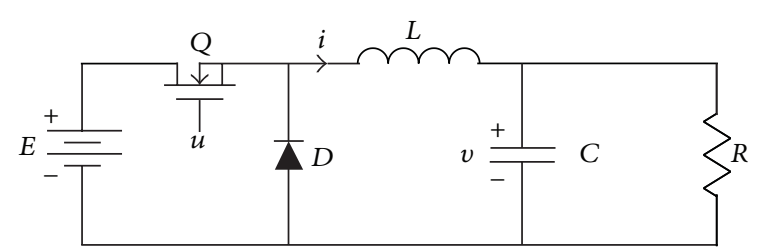

(a) Electronic circuit

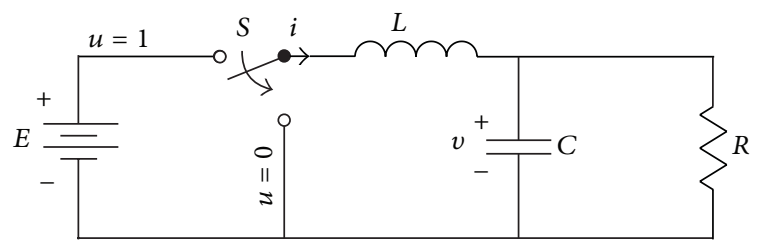

(b) Ideal circuit

FIGURE 1: DC/DC Buck power converter.

In practice, this transistor operates predominantly inside the cut-off and the saturation regions, excited by a switched signal. Therefore, when representing the converter ideal model, the transistor and the diode can be replaced by a switch, as shown in Figure 1(b).

Assuming that the converter is operating under continuous conduction mode, that is, the average value of the inductor current never drops to zero due to load variations (as stated in [54]), the switched dynamics of the DC/DC Buck converter is given by [23]:

$$
\begin{aligned}
& L \frac{d i}{d t}=-v+E u, \\
& C \frac{d v}{d t}=i-\frac{v}{R},
\end{aligned}
$$

where $i$ represents the inductor current, $v$ the output capacitor voltage, and $u$ the switch's position function (control input). The $u$ function is a discrete-valued signal taking values in the set $\{0,1\}$. The system parameters are established by the following: $L$, the inductance of the input circuit; $C$, the capacitance of the output filter; $R$, the output load resistance; and $E$, the external voltage supply.

Regarding the Buck converter matematical model used herein, it should be remarked that despite being a model where energy losses are not considered it has been extensively used in the literature $[23,28,30,35,42]$. The reason is its simplicity and relatively good accuracy, in comparison with more complex models that consider the internal resistance of the inductor, the model of the Shockley diode [55], and the model of the Ebers-Moll transistor [56].

The converter average model would be represented exactly by the same mathematical model (1), possibly by renaming the state variables with different symbols and by redefining the control variable $u$ as a sufficiently smooth function taking values in the compact interval of the real line $[0,1]$. In order to simplify the exposition, the model presented in (1) will be referred, replacing $u$ with $u_{\mathrm{av}}$, as 
the average model. This model is used to obtain a suitable average controller, for the average (continuous) input variable $u_{\mathrm{av}}$. A distinction will be made between the average control input, denoted by $u_{\mathrm{av}}$, and the switched control input, denoted by $u$. Then, the only feature that differentiates the average model from the switched model will be the control input.

Considering the aforementioned representation, the average model of the DC/DC Buck converter will be described by

$$
\begin{aligned}
L \frac{d i}{d t} & =-v+E u_{\mathrm{av}}, \\
C \frac{d v}{d t} & =i-\frac{v}{R}
\end{aligned}
$$

whose matrix representation is

$$
\begin{aligned}
& \dot{x}=A x+B u_{\mathrm{av}}, \\
& y=C x
\end{aligned}
$$

where $x=\left(\begin{array}{ll}i & v\end{array}\right)^{T}$ and

$$
A=\left(\begin{array}{cc}
0 & -\frac{1}{L} \\
\frac{1}{C} & -\frac{1}{R C}
\end{array}\right) ; \quad B=\left(\begin{array}{c}
\frac{E}{L} \\
0
\end{array}\right) ; \quad C=\left(\begin{array}{l}
0 \\
1
\end{array}\right)^{T} .
$$

According to [23], the steady state of $i$ and $v$, which is associated with the average model (2), for a constant control input $u_{\mathrm{av}}=U$ is determined by

$$
I=\frac{V}{R}, \quad V=E U
$$

Consequently, since $U \in[0,1]$, the DC/DC Buck converter output voltage is restricted to $0 \leq V \leq E$. Due to this fact, this topology is also known as step-down converter.

2.2. Average Flatness-Based Control. In this subsection, an average flatness-based controller is obtained for the DC/DC Buck converter. The principle of this approach is to find an output, referred to as flat, that along with its derivatives allows a differential parametrization of the system states and its input (see [57]).

The flat output of the DC/DC Buck converter is determined by

$$
F=\left(\begin{array}{ll}
0 & 1
\end{array}\right)(B: A)^{-1} x=\frac{L C}{E} v .
$$

Therefore, only the capacitor voltage is considered as its flat output, that is, $f=v$. In consequence, the differential parametrization associated with the converter is given by

$$
\begin{aligned}
v & =f, \\
i & =C \dot{v}+\frac{1}{R} v, \\
u_{\mathrm{av}} & =\frac{L C}{E} \ddot{v}+\frac{L}{R E} \dot{v}+\frac{1}{E} v .
\end{aligned}
$$

From (9), a selection of $u_{\mathrm{av}}$ defined by

$$
u_{\mathrm{av}}=\frac{L C}{E} \mu_{c}+\frac{L}{R E} \dot{v}+\frac{1}{E} v
$$

reduces the control problem to the following:

$$
\ddot{v}=\mu_{c}
$$

A convenient selection of the auxiliary input, $\mu_{c}$, that achieves the trajectory tracking task, that is, $v \rightarrow v^{*}$, is determined by

$$
\mu_{c}=\ddot{v}^{*}-\beta_{2}\left(\dot{v}-\dot{v}^{*}\right)-\beta_{1}\left(v-v^{*}\right)-\beta_{0} \int_{0}^{t}\left(v-v^{*}\right) d \tau,
$$

where $v^{*}$ is a desired time-varying trajectory that satisfies the restriction $0 \leq v^{*} \leq E$, in accordance with (5).

Introducing (12) into (11) and defining $e=v-v^{*}$, after deriving the resulting equation, the following closed-loop tracking error dynamics is obtained:

$$
\dddot{e}+\beta_{2} \ddot{e}+\beta_{1} \dot{e}+\beta_{0} e=0,
$$

which has the following associated characteristic polynomial:

$$
P(s)=s^{3}+\beta_{2} s^{2}+\beta_{1} s+\beta_{0} .
$$

The values of the design parameters $\beta_{2}, \beta_{1}$, and $\beta_{0}$ are chosen so that the closed-loop characteristic polynomial (14) has all of its roots in the left half of the complex plane. Thus, the controller parameters were chosen so as to achieve the following desired closed-loop characteristic polynomial:

$$
P_{d}=(s+a)\left(s^{2}+2 \zeta \omega_{n} s+\omega_{n}^{2}\right)
$$

considering that $a>0, \omega_{n}>0$, and $\zeta>0$. Hence, the gains of the flatness-based controller are given by

$$
\beta_{2}=2 \zeta \omega_{n}+a, \quad \beta_{1}=2 a \zeta \omega_{n}+\omega_{n}^{2}, \quad \beta_{0}=a \omega_{n}^{2} .
$$

2.3. Implementation of the Average Control. The average control determined by (10) and (12) cannot appropriately govern the DC/DC Buck converter's switch. Hence, the controller is implemented through either a PWM or a $\Sigma-\Delta$-modulator. Figure 2 presents a schematic diagram illustrating the implementation.

The PWM's characteristics, operation principles, and applications to power electronics have been widely documented, for example, [58]. Meanwhile, the $\Sigma-\Delta$-modulator has been mainly studied from a signal encoding approach (e.g., $[25,26])$. And the $\Sigma$ - $\Delta$-modulator has been applied in power electronics recently, relative to PWM. An example of this can be found in [59], where the main qualities of the $\Sigma-\Delta$-modulator in this area are described. Finally, as noticed in Section 1, reported works associated with the implementation of average controllers via the $\Sigma-\Delta$-modulator in power converters are few, unlike the PWM related works in this direction. In this respect, the following sliding mode 


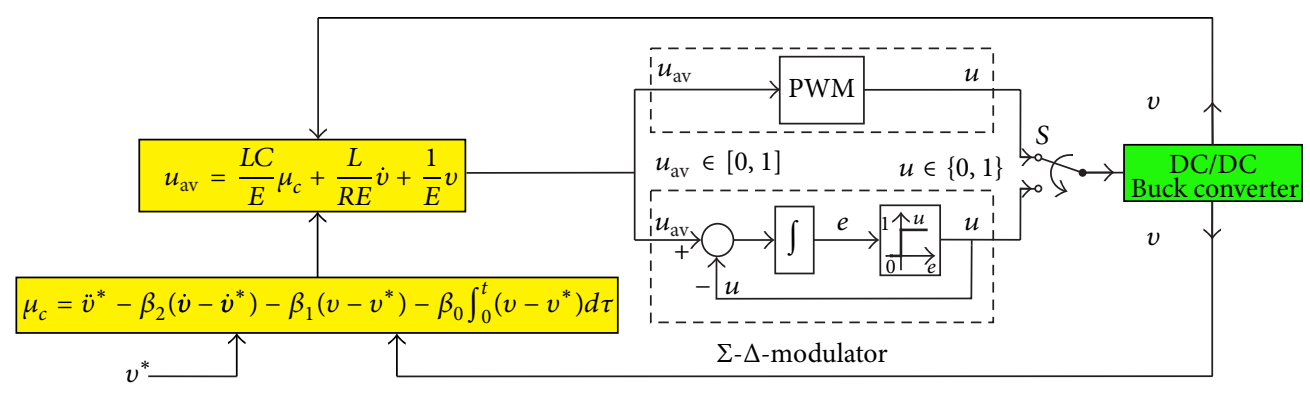

FIgURE 2: Flatness-based control developed.

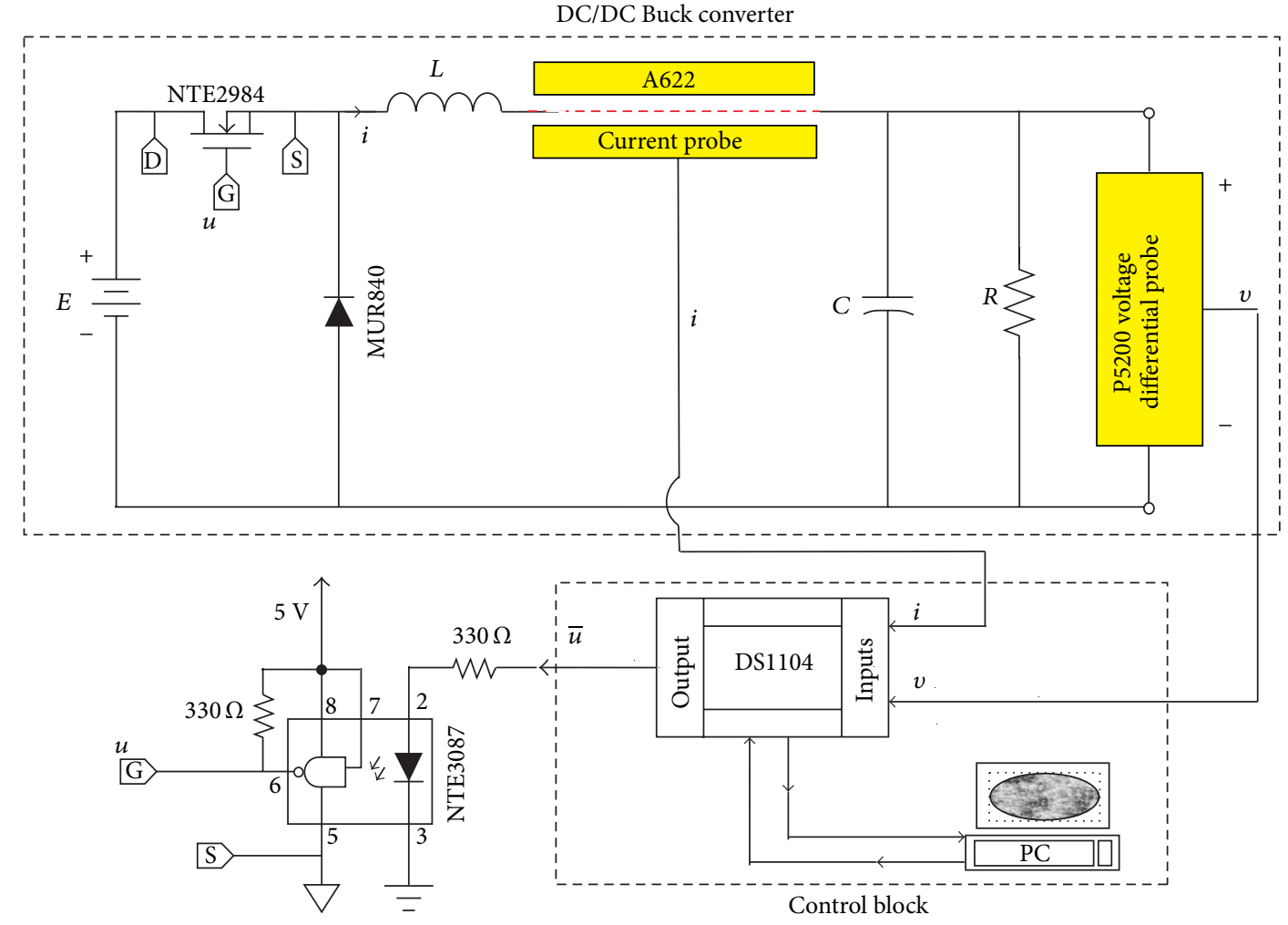

FIgURE 3: Connection diagram used for the experimentation.

implementation is achieved, for the previously developed average flatness-based control, by using a $\Sigma$ - $\Delta$-modulator, as discussed in $[22,23]$, that is,

$$
\begin{aligned}
& u=\frac{1}{2}[1+\operatorname{sign} e], \\
& \dot{e}=u_{\mathrm{av}}-u,
\end{aligned}
$$

with $u_{\text {av }}$ defined by (10). Using [22, 23], the Appendix presented in this paper describes the most relevant characteristics associated with the implementation of average controllers via a $\Sigma$ - $\Delta$-modulator.

\section{Experimental Implementation of the Average Controller}

This section describes the experimental switched implementation, via either a PWM or a $\Sigma$ - $\Delta$-modulator, of the average flatness-based controller developed in the previous section.

In order to accomplish the controller implementation on the converter, a DS1104 electronic card from dSPACE, along with its application software, and Matlab-Simulink were used. A diagram of the connections employed to develop the experiments is shown in Figure 3. This diagram includes two blocks: the DC/DC Buck converter and the Control block.

The DC/DC Buck converter block corresponds to the construction of the electronic circuit associated with Figure 1(a), of which the electronic components' values are

$$
\begin{aligned}
L=68.6 \mathrm{mH}, \quad C & =114.4 \mu \mathrm{F}, \quad R=60 \Omega, \\
E & =48 \mathrm{~V} .
\end{aligned}
$$




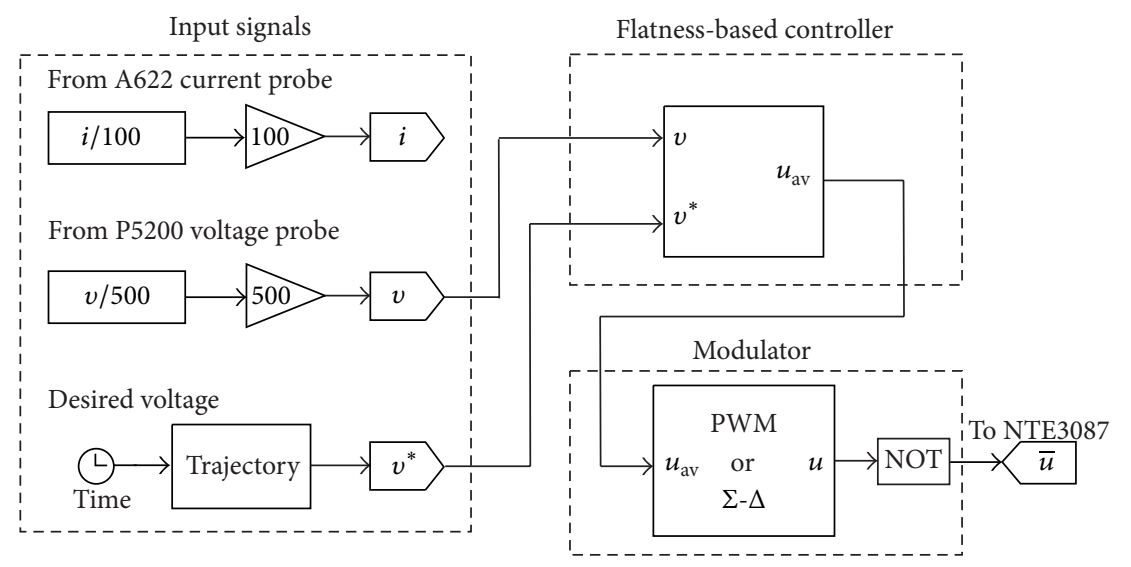

FIgURE 4: Control block adapted to Matlab-Simulink.

The Control block is programmed using Matlab-Simulink and has the following three stages, which are shown in Figure 4.

(i) Input signals stage, which carries out the measurements of $i$ and $v$ : the first signal is determined using a Tektronix A622 AC/DC current probe and the second one is obtained from a Tektronix P5200 voltage differential probe. In addition, in this stage the desired voltage $v^{*}$ is generated. For the experimental results obtained, the desired voltage profile was proposed as

$v^{*}(t)=\frac{\pi}{2}\left\{6+\left[1-e^{-2 t^{2}}\right]\left[1+5 \sin \left(\pi t+\frac{\pi}{3}\right)\right]\right\}$.

(ii) Flatness-based controller stage, which is meant to generate the average control signal $u_{\mathrm{av}}$, determined by (10) and (12): the parameters associated with (16) were chosen as

$$
a=50, \quad \zeta=0.6, \quad \omega_{n}=500 .
$$

It is important to underline that in the implementation of the average control law $u_{\mathrm{av}}$ only $v$ is required, while $i$ is measured only in order to observe its dynamic evolution.

(iii) Modulator stage, which converts the average control signal into a switched signal, via either a PWM or a $\Sigma$ - $\Delta$-modulator: two characteristics of this stage are highlighted: (1) it produces the complement of $u$, that is, $\bar{u}$, which will appropriately activate the NTE2984 Mosfet since the NTE3087 optocoupler inverts the logical input; (2) following the analysis presented in [50], since the proposed sampling frequency for the $\Sigma$ - $\Delta$-modulator was $25 \mathrm{kHz}$, a corresponding frequency for the PWM that achieves a similar efficiency to that of the $\Sigma-\Delta$-modulator is $12.5 \mathrm{kHz}$. In particular, an asymmetric PWM of $50 \mathrm{~ns}$ resolution generated by the DS1104 was employed here. It is important to underline that there is no significant restriction on the implementation of both modulators, since their experimental implementation can be provided by low-cost electronic circuits.

\section{Results and Discussion}

This section presents the experimental results associated with the trajectory tracking task, as well as a discussion of the obtained results. The approach used in this section is meant to assess the tracking performance of the DC/DC Buck converter when the average control law is implemented through either the PWM or the $\Sigma$ - $\Delta$-modulator. Here, the results are quantified by using the integral of squared error (ISE) performance index given by

$$
\text { ISE }=\int_{0}^{t}\left[v(t)-v^{*}(t)\right]^{2} d t .
$$

Despite the fact that this index has been commonly used to compare the performance of different control techniques (see [60]), in this research the ISE index is meant to compare the tracking performance of the same controller when it is implemented through different modulators, indicating which one is more suitable for the trajectory tracking task.

4.1. Experimental Results. The experimental results associated with $\left(v, i, u_{\mathrm{av}}\right)$ and $\left(v, i, u, u_{\mathrm{av}}\right)$ are obtained in the implementation of the average flatness-based controller via the PWM and the $\Sigma-\Delta$-modulator, respectively, for the four following cases.

(i) The first one is when the system's nominal parameters, defined by (18), remain unchanged. The corresponding experimental results obtained for the PWM and the $\Sigma$ - $\Delta$-modulator are shown in Figures 5 and 6, respectively.

(ii) The second one is when there is an abrupt change in the load $R$, defined by

$$
R_{m}= \begin{cases}R & \text { for } 0 \leq t<2 \mathrm{~s}, \\ 34 \% R \approx 20 \Omega & \text { for } t \geq 2 \mathrm{~s} .\end{cases}
$$




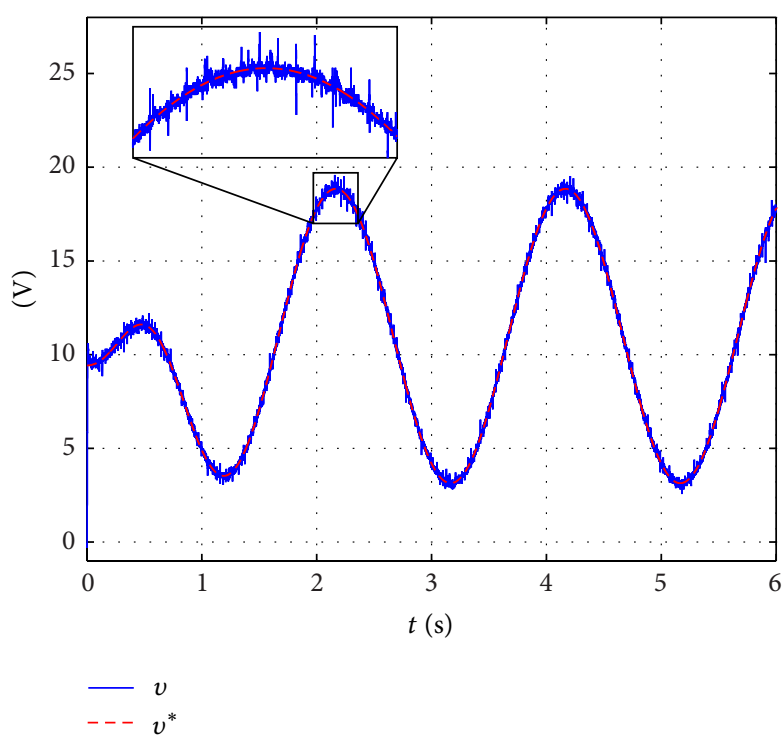

(a)
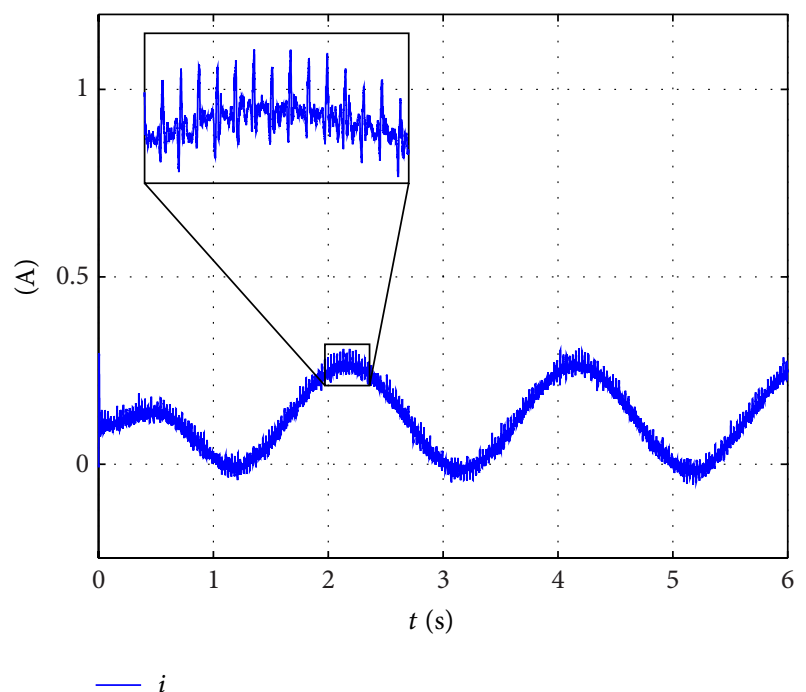

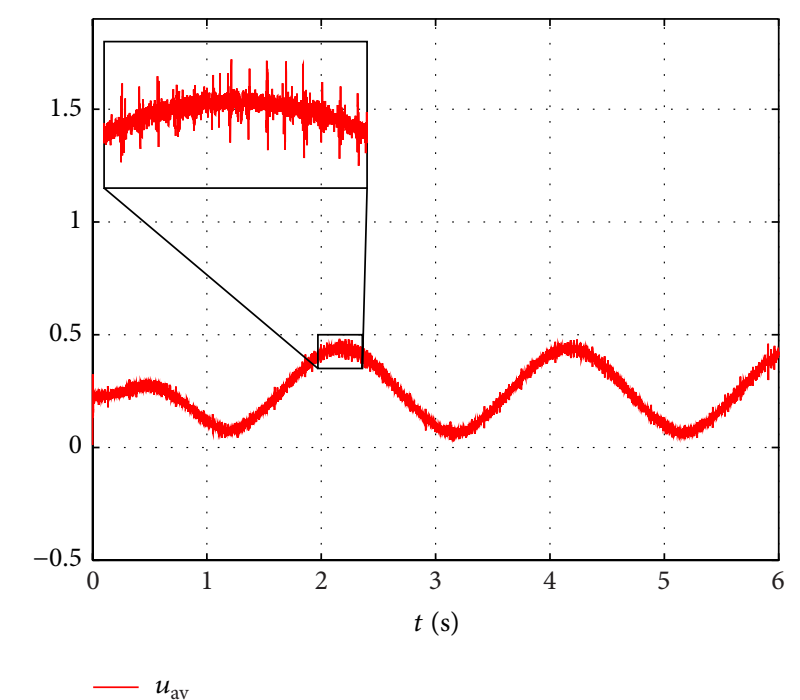

(b)

(c)

FIgure 5: Case (i) via PWM.

It is worth mentioning that this change was chosen in view of the fact that in this situation the converter current $i$ increases considerably, which can be verified by (5), and the trajectory tracking task can still be accomplished. In Figures 7 and 8, the obtained results are presented when the controller is implemented via the PWM and the $\Sigma$ - $\Delta$-modulator, respectively.

(iii) The third one is when there is a perturbation associated with the supply voltage $E$. Herein, this one is selected as

$$
E_{m}= \begin{cases}E & \text { for } 0 \leq t<2.5 \mathrm{~s}, \\ 80 \% E=38.4 \mathrm{~V} & \text { for } t \geq 2.5 \mathrm{~s} .\end{cases}
$$

The reasoning behind choosing this perturbation is similar to the previous one, when the load $R$ changes, but now this reasoning is applied to the average control $u_{\mathrm{av}}$, verified by (5). In this case the experimental results associated with the PWM and the $\Sigma-\Delta$ modulator are shown in Figures 9 and 10, respectively.

(iv) The fourth one is when there is an abrupt change in the dynamics of the system, which was not considered while designing the average controller. In this case, the system's dynamics was modified via the parallel connection of $R$ with a DC motor, namely,

$$
R_{m}= \begin{cases}R & \text { for } 0 \leq t<3 \mathrm{~s}, \\ R \| \text { DC motor } & \text { for } t \geq 3 \mathrm{~s} .\end{cases}
$$

For this research, the DC motor used is an Engel GNM5440E (1600 rpm @ 24 V and a gearbox G3.1 


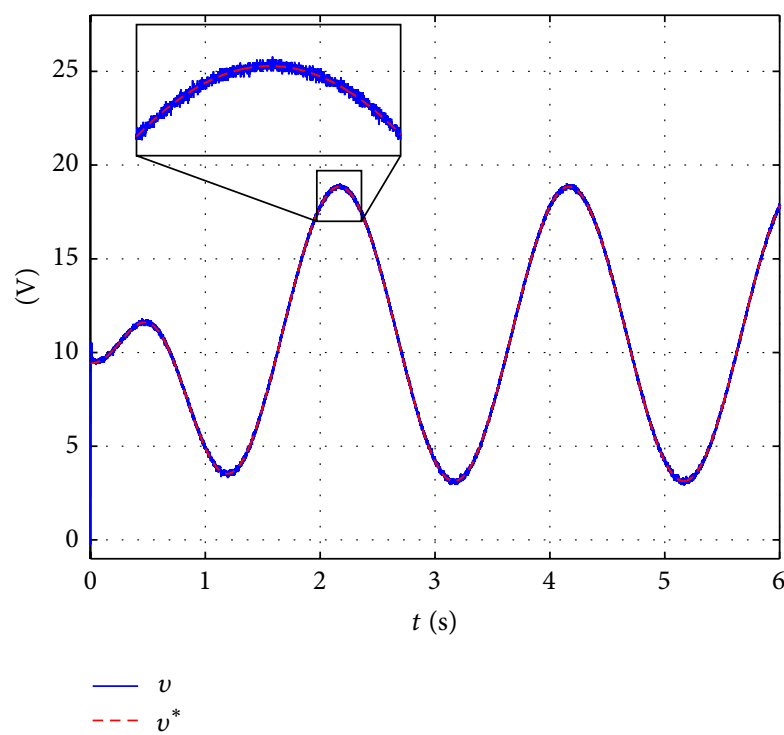

(a)
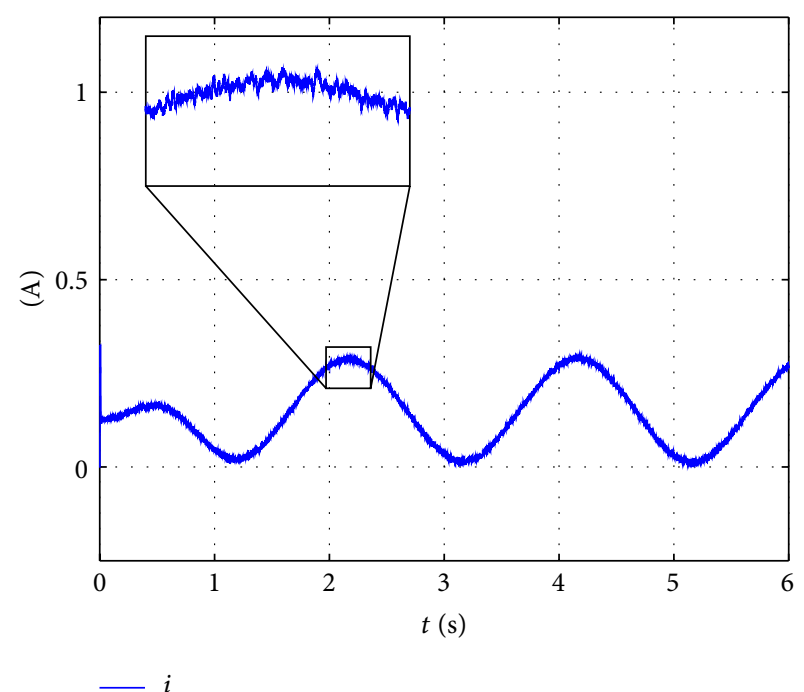

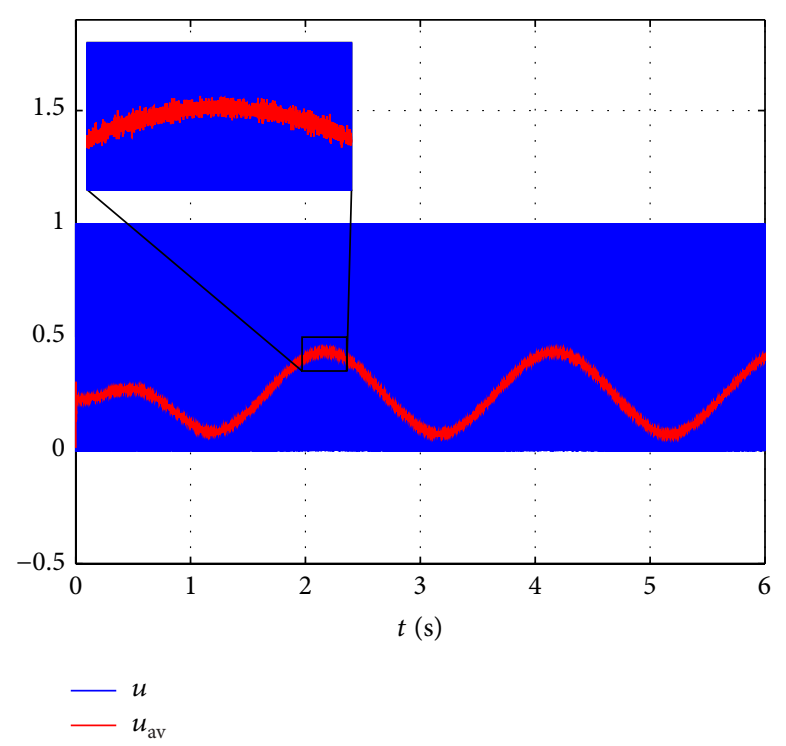

(b)

(c)

Figure 6: Case (i) via $\Sigma$ - $\Delta$-modulator.

with a $14.5: 1$ reduction ratio). The corresponding experimental results obtained in this case are illustrated in Figures 11 and 12, for the PWM and the $\Sigma$ - $\Delta$-modulator, respectively.

In order to observe in detail the performance of the average controller implemented through the PWM and the $\Sigma$ - $\Delta$-modulator, a zoom-in was presented in the experimental results. Thus, in Figures 5 and 6 there was a focus on where the differences between the waveforms are most noticeable, whereas, in Figures 7 to 12, there was a focus on the system response when the abrupt changes occur.

4.2. Discussion of the Results. In the experimental results obtained, it can be observed how the implementation of the average controller via the $\Sigma$ - $\Delta$-modulator, in comparison with the one via the PWM, provides, for all the signals of the DC/DC Buck converter, a lower amplitude ripple and, roughly speaking, a better filter (see Figures 5 to 12 ), attributable to the noise-shaping properties of the $\Sigma$ - $\Delta$-modulator.

To evaluate the experimental results, the ISE index is used to quantify the performance achieved in the trajectory tracking task when the average controller is implemented through each modulator. The ISE performance indices obtained in the experimental results are shown in Figure 13, where the smaller values (better performance) provided by the $\Sigma-\Delta$ modulator through all the reported cases are consistent with the differences stated previously. Likewise, it was observed 


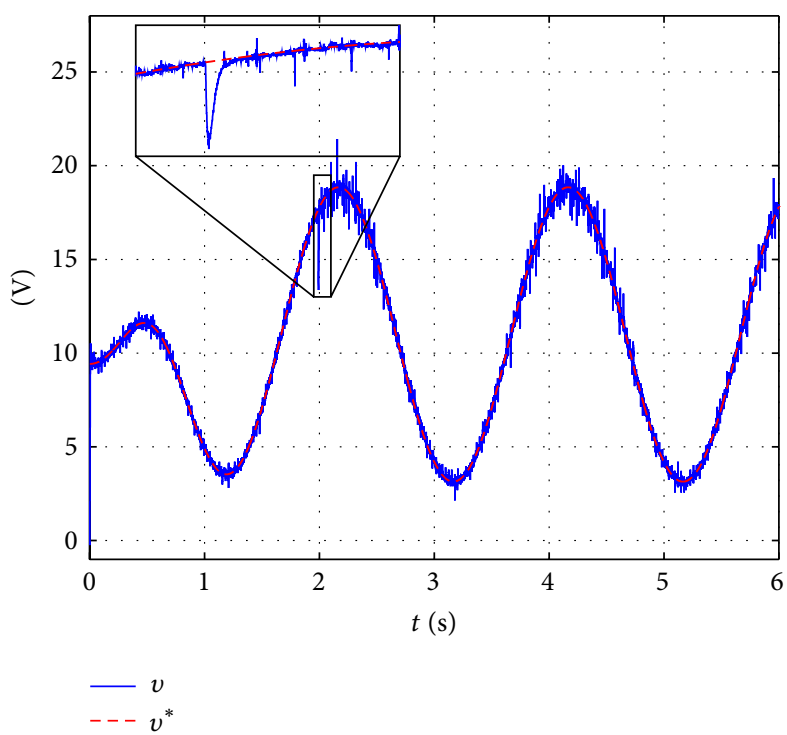

(a)

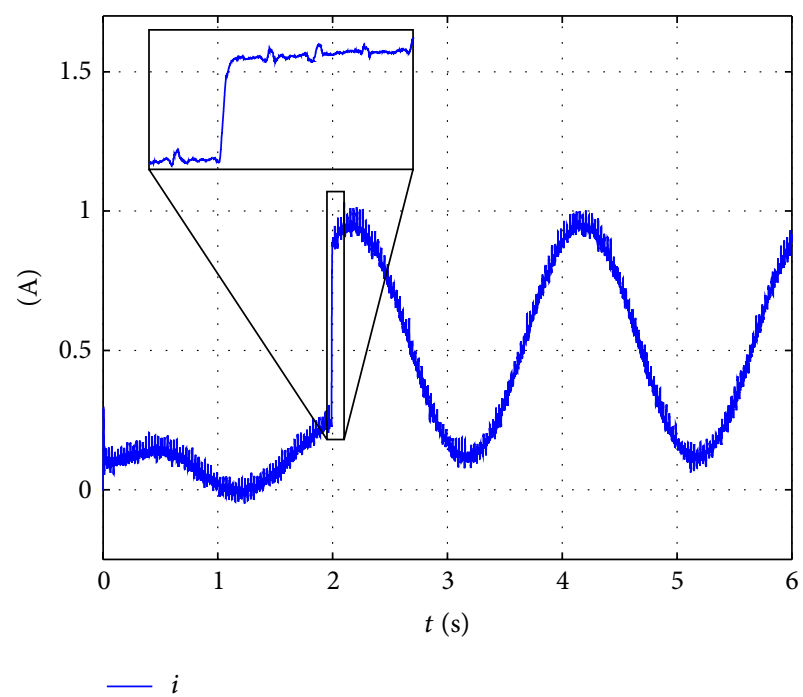

(b)

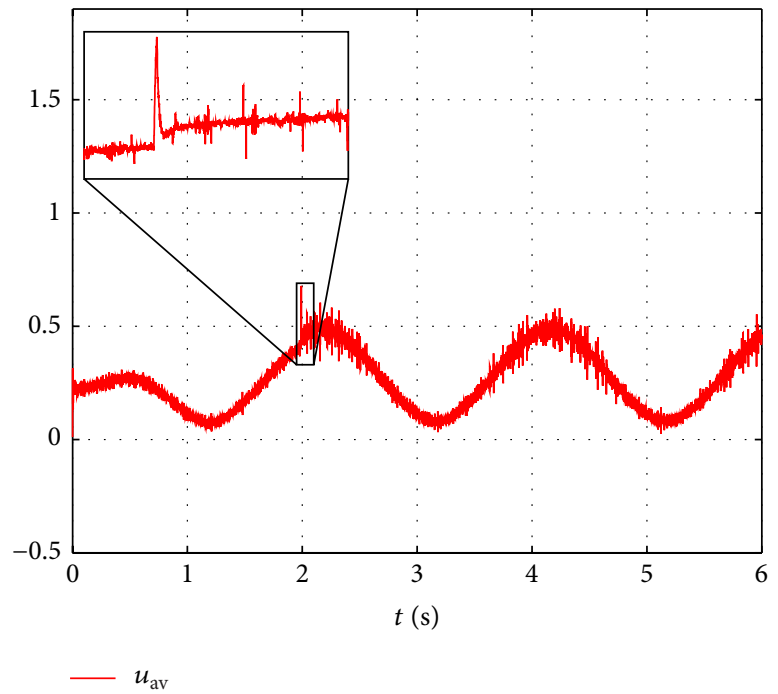

(c)

Figure 7: Case (ii) via PWM.

that the dynamic responses through both modulators were similar while the system was undergoing the abrupt changes (see Figures 7 to 12). In consequence, it can be stated that the average controller implementation via the $\Sigma-\Delta$-modulator presents a better, or at least similar, performance, than the one via the PWM.

The following aspects of the experimental results should be taken into consideration.

(i) Since the implementation of the average controller via the $\Sigma$ - $\Delta$-modulator shows the best results, the application of new controllers using this modulator for switched systems should be subject of more future research. (ii) Albeit the controller based on differential flatness is robust against parametric uncertainties, it is important to note that its implementation may be less feasible and applicable, since it leads to a long mathematical controller (see (10) and (12)) and its implementation with low-cost hardware might be more complex. Thus, it would be convenient to propose more feasible and applicable controllers for the trajectory tracking task via the $\Sigma$ - $\Delta$-modulator.

\section{Conclusions}

In this research, an average trajectory tracking controller was implemented for a DC/DC Buck converter via either a PWM 


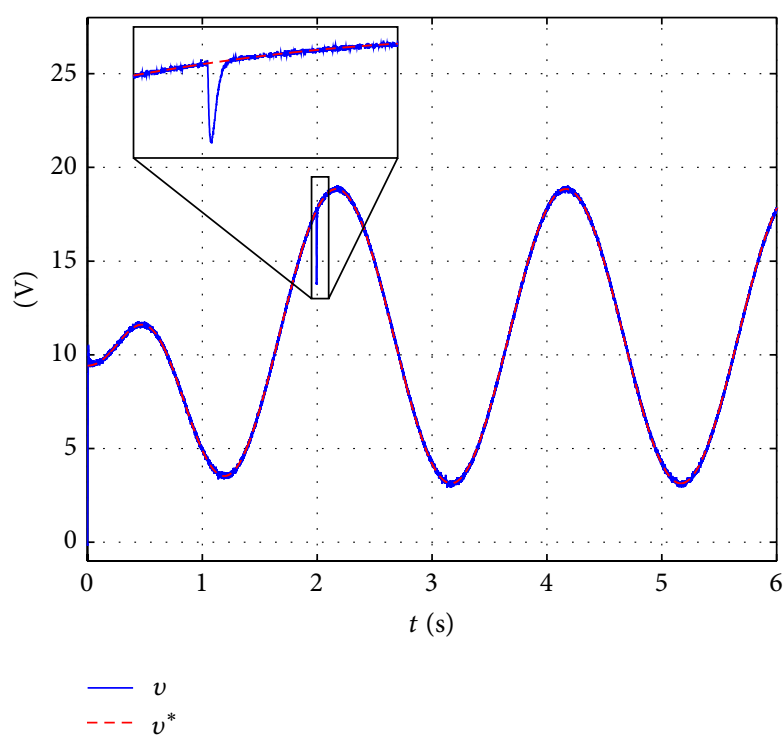

(a)

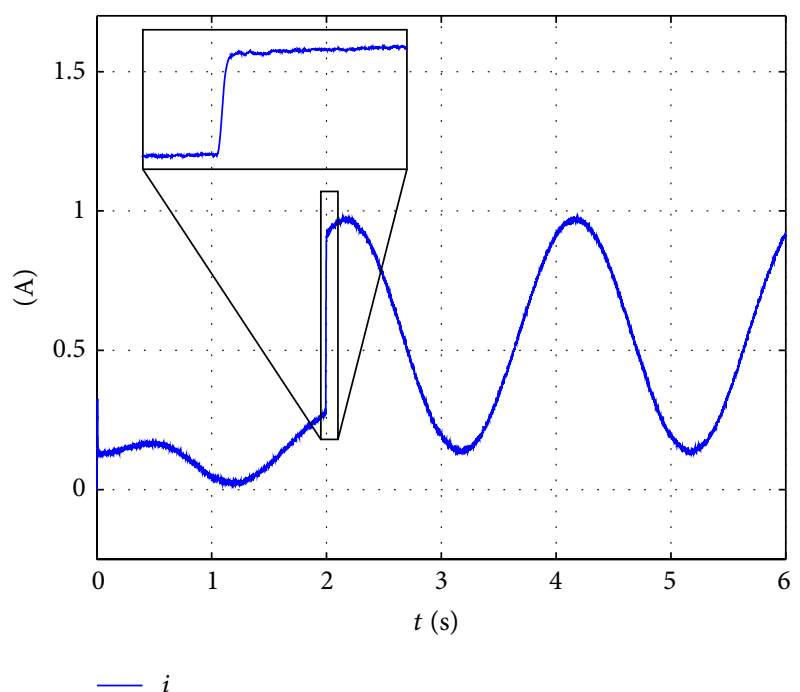

(b)

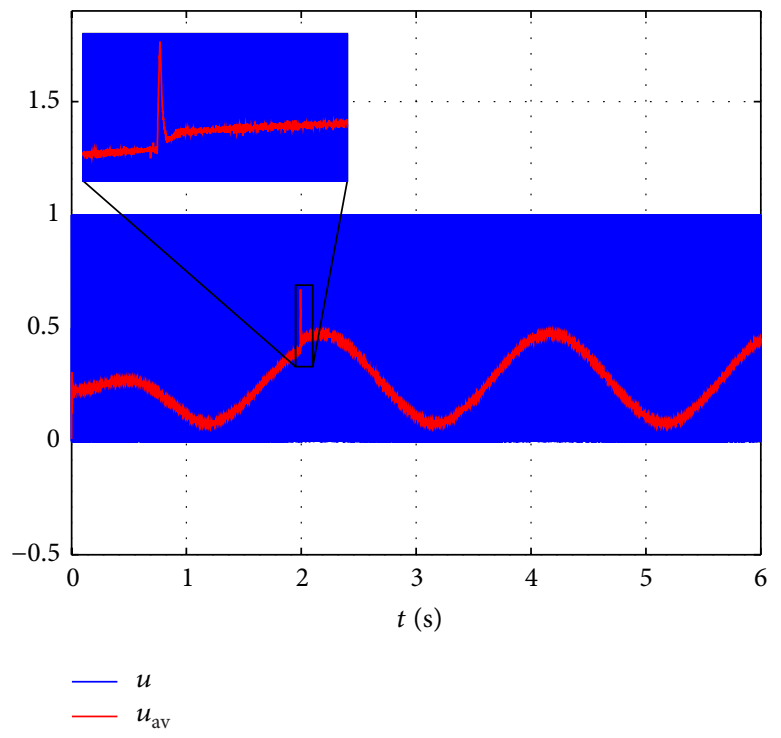

(c)

Figure 8: Case (ii) via $\Sigma$ - $\Delta$-modulator.

or a $\Sigma$ - $\Delta$-modulator. Experimental results were obtained and compared, aiming to infer for the first time which of these modulators is more advantageous for accomplishing the trajectory tracking task in power converters. In order to obtain a fair comparison, both modulators were set up with the same average control law, identical operational characteristics, and frequencies with similar efficiency. Furthermore, to provide a more exhaustive comparison, both modulators' performances were tested under abrupt perturbations associated with the converter.

Assessing the experimental results presented in Figures 5 to 12 and the ISE performance indices shown in Figure 13, the advantageous noise-shaping properties of the $\Sigma-\Delta$-modulator were verified for the trajectory tracking task in the DC/DC
Buck converter, transcending the regulation task identified in [50]. Also, the performance of the implementation via the $\Sigma-\Delta$-modulator in the trajectory tracking task was proved to be better than, or at least similar to, that via the PWM. Thus, this evidence demonstrates the $\Sigma-\Delta$-modulator is more suitable than the PWM in applications to the trajectory tracking task in DC/DC Buck converters where a lower ripple and a smoother output voltage are required.

Finally, as a possible direction for future research, this methodology can be used in other DC/DC power converter topologies, to determine whether the $\Sigma$ - $\Delta$-modulator provides a better performance than that provided by the PWM when implementing average control laws for the trajectory tracking task. Also, it would be convenient to propose new 


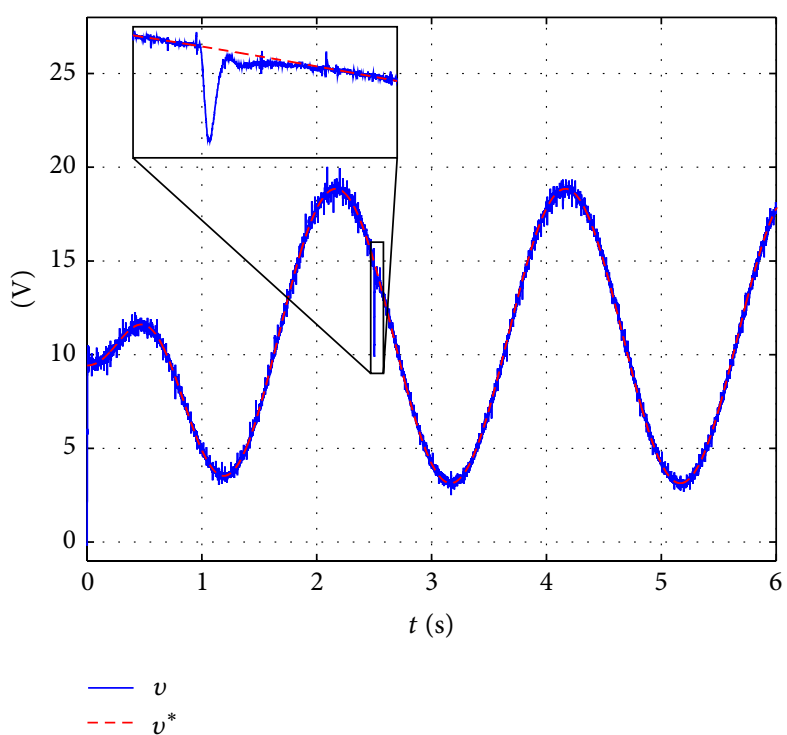

(a)

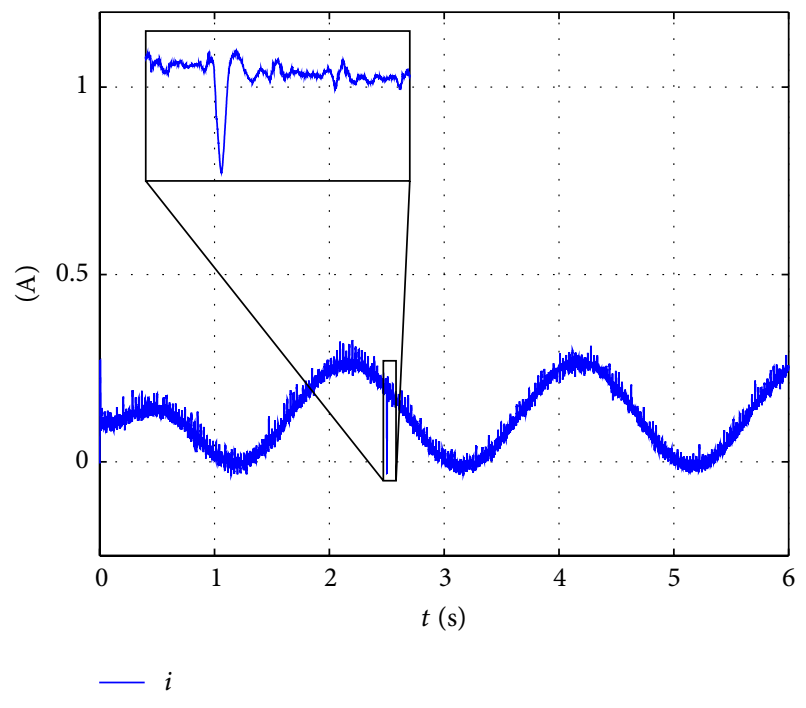

(b)

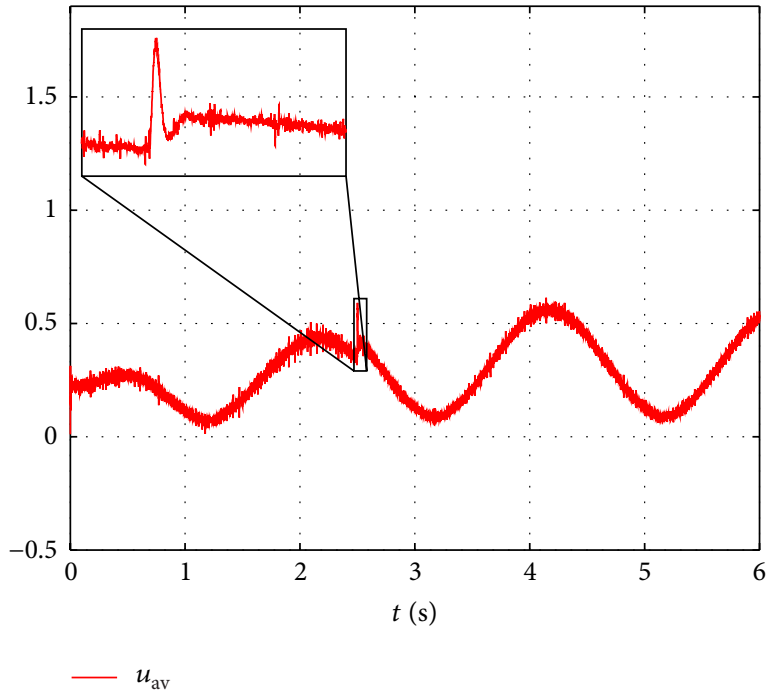

(c)

Figure 9: Case (iii) via PWM.

controllers that lead to shorter mathematical expressions, more feasible and applicable to implement them via lowcost hardware. Another interesting future research topic is applying sliding mode or $H_{\infty}$ controllers via a fuzzy control approach (see details in [17-19]), for the trajectory tracking task in DC/DC power converters.

\section{Appendix}

\section{A. $\Sigma$ - $\Delta$-Modulator}

Consider the basic block diagram of Figure 14, reminiscent of a first order $\Sigma$ - $\Delta$-modulator block but with a binary valued forward nonlinearity, taking values in the discrete set $\{0,1\}$.
For ease of reference, such a block is addressed simply as a $\Sigma$ - $\Delta$-modulator. The following theorem summarizes the relation of the considered modulator with sliding mode control while establishing the basic features of its inputoutput performance.

Theorem A.1. Consider the $\Sigma$ - $\Delta$-modulator of Figure 14, given a sufficiently smooth, bounded, signal $\mu(t)$, and then the integral error signal, $e(t)$, converges to zero in a finite time, $t_{h}$. Moreover, from any arbitrary initial value, $e\left(t_{0}\right)$, a sliding motion exists on the perfect encoding condition surface, represented by $e=0$, for all $t>t_{h}$, provided that the following encoding condition is satisfied for all $t$ :

$$
0<\mu(t)<1 .
$$




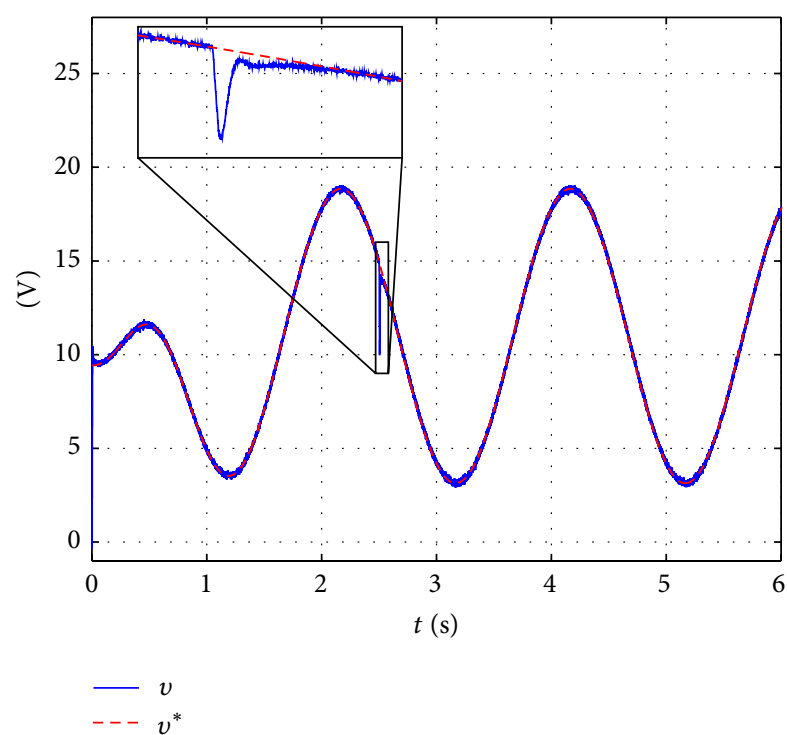

(a)
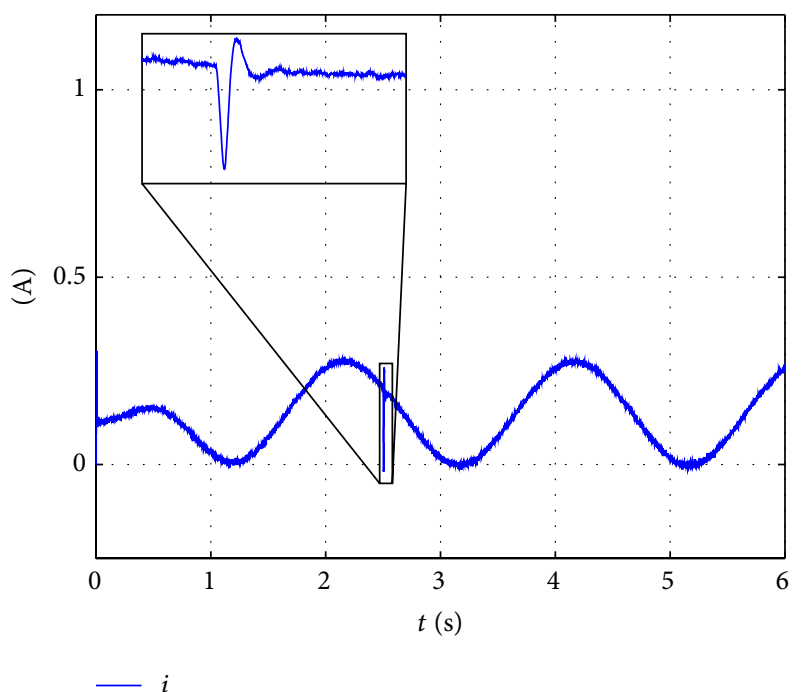

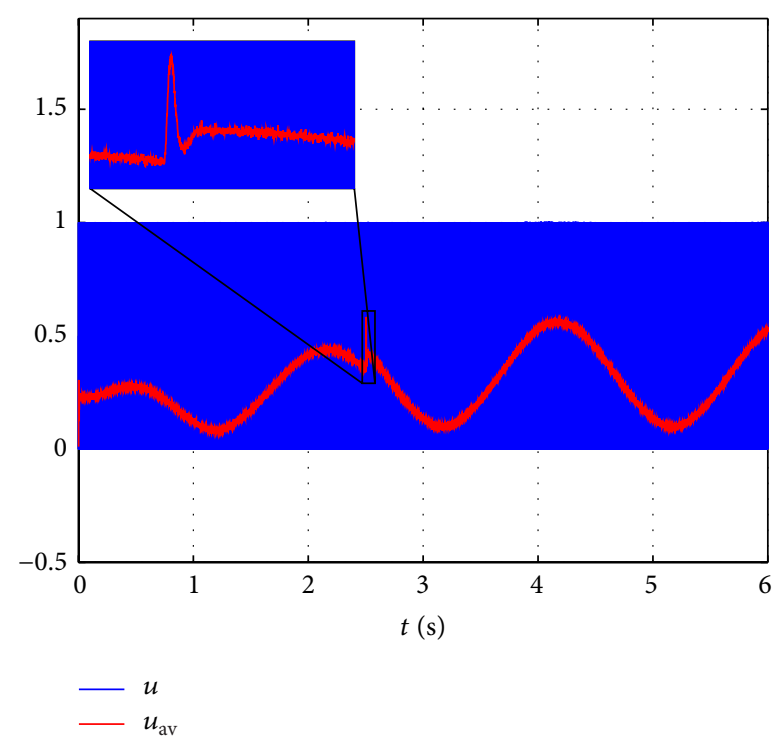

(b)

(c)

Figure 10: Case (iii) via $\Sigma$ - $\Delta$-modulator.

Proof. From Figure 14, the variables in the $\Sigma-\Delta$-modulator satisfy the following relations:

$$
\begin{aligned}
\dot{e} & =\mu(t)-u, \\
u & =\frac{1}{2}[1+\operatorname{sign}(e)] .
\end{aligned}
$$

The quantity $e \dot{e}$ is given by

$$
\begin{aligned}
e \dot{e} & =e\left[\mu-\frac{1}{2}(1+\operatorname{sign}(e))\right] \\
& =-|e|\left[\frac{1}{2}(1+\operatorname{sign}(e))-\mu \operatorname{sign}(e)\right] .
\end{aligned}
$$

For $e>0, e \dot{e}=-e(1-\mu)$, which, according to the assumption in (A.1), leads to $e \dot{e}<0$. On the other hand, when $e<0$, $e \dot{e}=-|e| \mu<0$ is obtained. A sliding regime exists then on $e=0$ for all time $t$ after the hitting time $t_{h}$ [2]. Under ideal sliding or encoding conditions $e=0$ and $\dot{e}=0$, so called, equivalent value of the switched output signal $u$, denoted by $u_{\text {eq }}(t)$, satisfies $u_{\mathrm{eq}}(t)=\mu(t)$.

An estimate of the hitting time $t_{h}$ is obtained by examining the modulator system equations with the worst possible bound for the input signal $\mu$ in each of the conditions $e>0$ and $e<0$, along with the corresponding value of $u$. Consider then $e(0)>0$ at time $t=0$, for all $0<t \leq t_{h}$ the following is obtained

$$
\begin{aligned}
e(t) & =e(0)+\int_{0}^{t}(\mu(\sigma)-u(\sigma)) d \sigma \\
& \leq e(0)+t\left[\sup _{t \in[0, t]} \mu(t)-1\right] \\
& <e(0)+t_{h}\left[\sup _{t} \mu(t)-1\right] .
\end{aligned}
$$




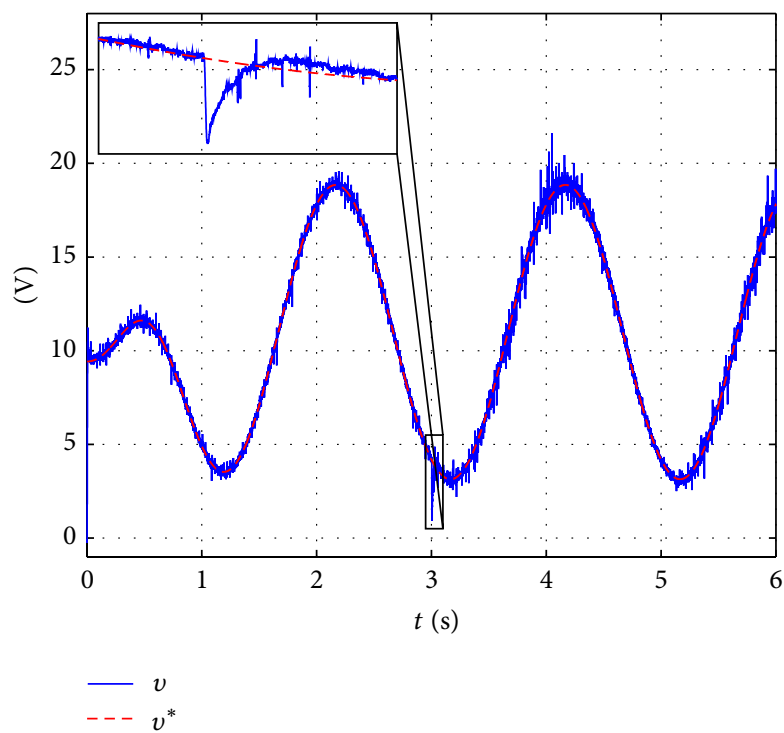

(a)

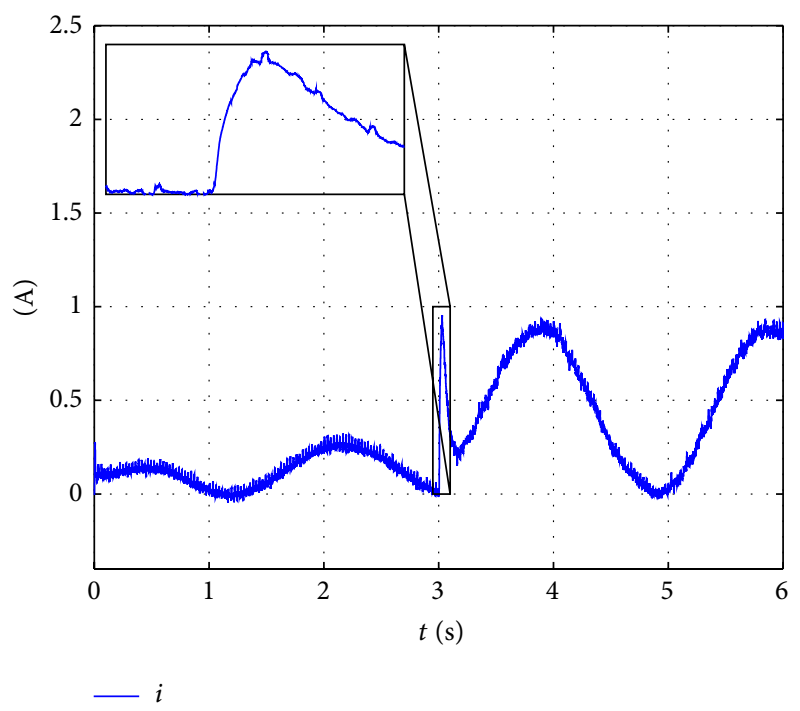

(b)

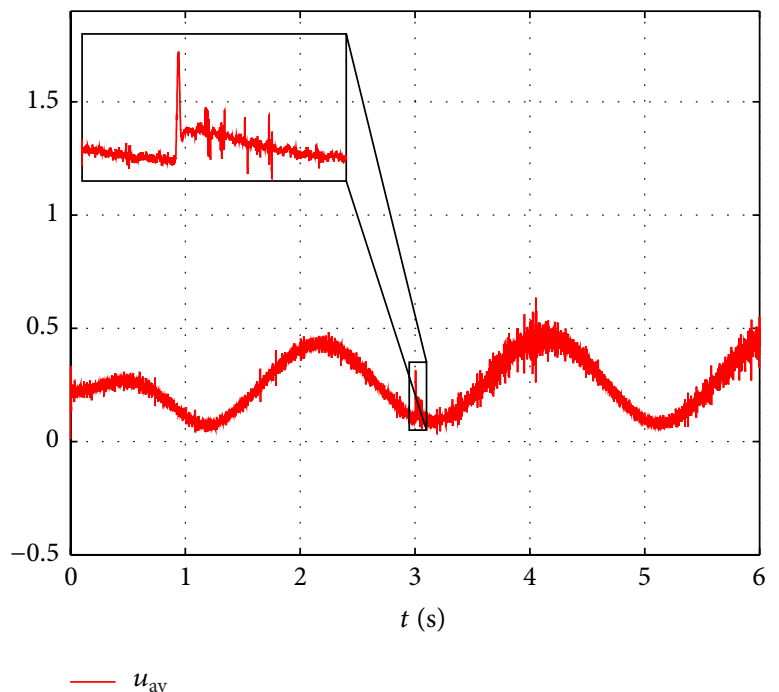

(c)

FIgURE 11: Case (iv) via PWM.

Since $e\left(t_{h}\right)=0$,

$$
t_{h} \leq \frac{e(0)}{1-\sup _{t} \mu(t)} .
$$

The average $\Sigma$ - $\Delta$-modulator output $u_{\text {eq }}$ ideally yields the modulator's input signal $\mu(t)$ in an equivalent control sense [2]. The role of the above described $\Sigma-\Delta$-modulator in sliding mode control schemes, avoiding full state measurements and using average based controllers, will be clear from the developments presented below.

A.1. Use of a $\Sigma-\Delta$-Modulator in the Sliding Mode Control Implementation of an Average Feedback Controller Design. Suppose a smooth nonlinear system of the form $\dot{x}=f(x)+$ $u g(x)$ with $u$ being a continuous control input signal that, due to some physical limitations, requires to be strictly bounded by the closed interval $[0,1]$. Suppose, moreover, that a dynamic output feedback controller of the form $u=$ $-\kappa(y, \zeta), \dot{\zeta}=\varphi(y, \zeta)$ has been specified, achieving desirable closed loop performance features. Assume, furthermore, that, for some reasonable set of initial states of the system (and of the dynamic controller), the values of the generated feedback signal function, $u(t)$, are uniformly strictly bounded by the closed interval $[0,1]$.

If an additional implementation requirement entitles now that the control input $u$ of the system is no longer allowed to continuously take values within the interval $[0,1]$, but that it may only take values in the discrete set $\{0,1\}$, the natural question is: how can we now implement the previously derived continuous controller so that we can recover, possibly 


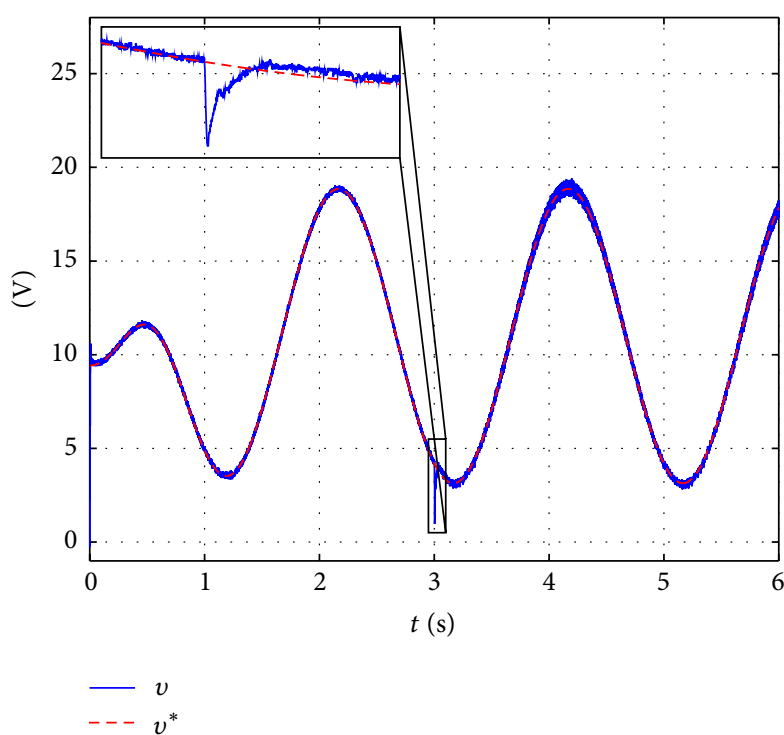

(a)

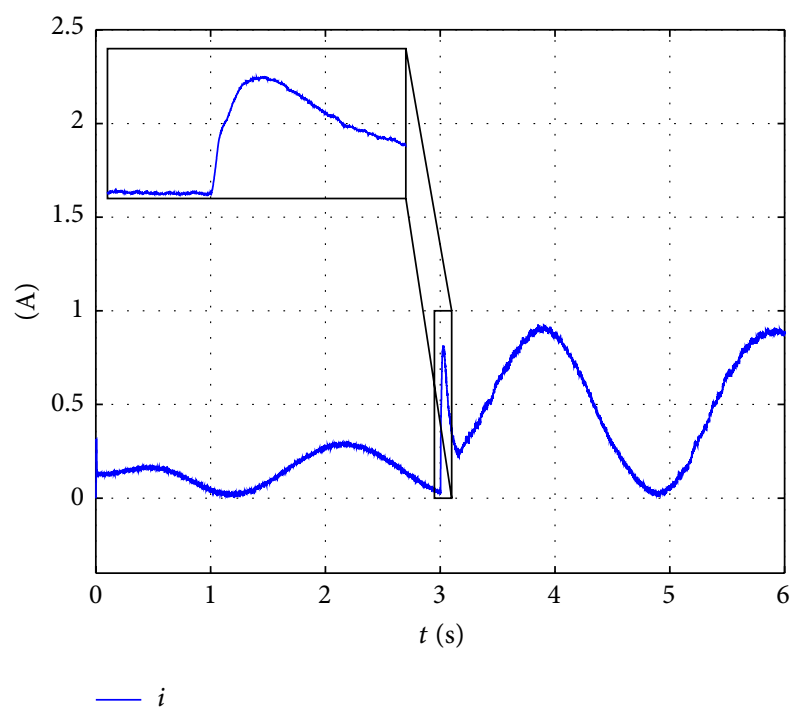

(b)

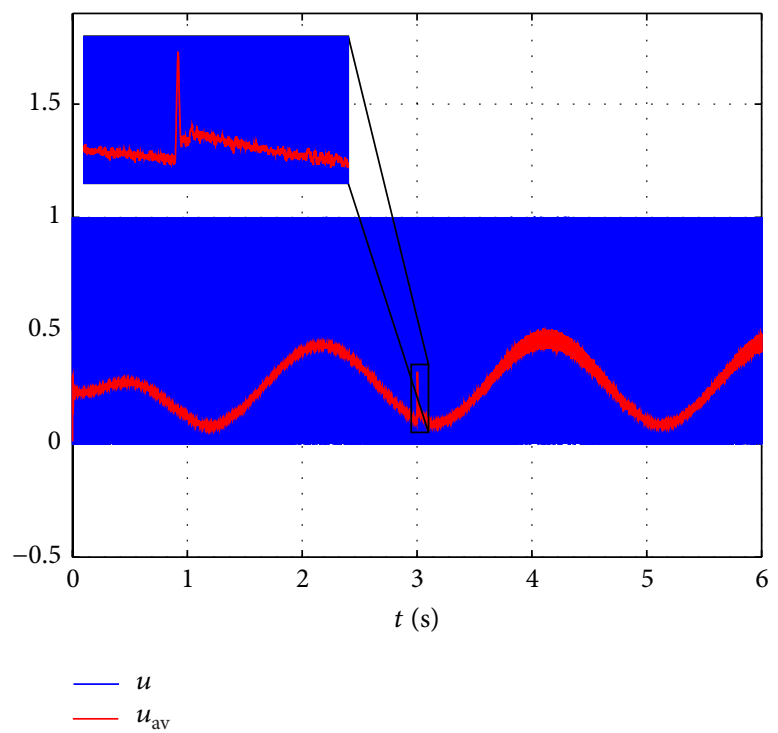

(c)

Figure 12: Case (iv) via $\Sigma$ - $\Delta$-modulator.

in an average sense, the desirable features of the derived dynamic output feedback controller design in view of the newly imposed actuator restriction?

The answer is clearly given by the average features of the previously considered $\Sigma-\Delta$-modulator. Recall, incidentally, that the output signal of such a modulator is restricted to take values, precisely, in the discrete set $\{0,1\}$. Thus, if the output of the designed continuous controller, call it $\mu(t)=u_{\mathrm{av}}(t)$, is fed into the proposed $\Sigma-\Delta$-modulator, the output signal of the modulator reproduces, on the average, the required control signal $u_{\mathrm{av}}$, but in a switched manner.

Then the following general result concerning the control of nonlinear systems through sliding modes synthesized on the basis of an average feedback controller and a $\Sigma$ - $\Delta$ modulator is obtained. It only deals with the dynamic output feedback controller case for the stabilization problem around an equilibrium. However, the result can also be easily extended to be valid for trajectory tracking problems.

Theorem A.2. Consider the following smooth nonlinear single input, $n$-dimensional system: $\dot{x}=f(x)+u g(x)$, with the smooth scalar output map, $y=h(x)$. Assume the dynamic smooth output feedback controller $u=-\kappa(y, \zeta), \dot{\zeta}=\varphi(y, \zeta)$, with $\zeta \in R^{p}$, locally (globally, semiglobally) asymptotically stabilizes the system towards a desired constant equilibrium state, denoted by X. Assume, furthermore, that the control 


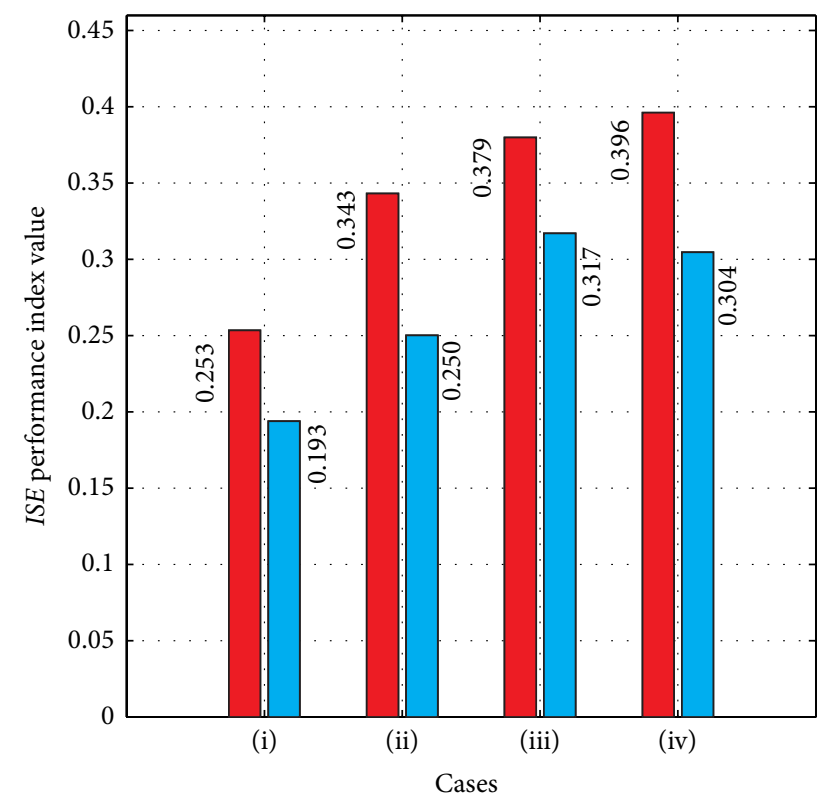

PWM
$\Sigma$ - $\Delta$-modulator

FIGURE 13: Values of the modulators' ISE performance indices.

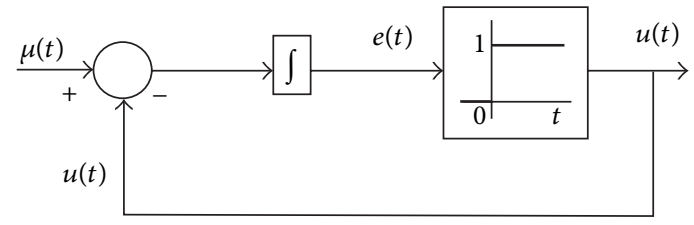

FIGURE 14: First order $\Sigma-\Delta$-modulator.

signal, $u$, is uniformly strictly bounded by the closed interval $[0,1]$ of the real line. Then the closed loop system,

$$
\begin{aligned}
\dot{x} & =f(x)+u g(x), \\
y & =h(x), \\
u_{a v}(y, \zeta) & =-\kappa(y, \zeta, X), \\
\dot{\zeta} & =\varphi(y, \zeta, X), \\
u & =\frac{1}{2}[1+\operatorname{sign} e], \\
\dot{e} & =u_{a v}(y, \zeta)-u,
\end{aligned}
$$

exhibits an ideal sliding dynamics which is locally (globally, semiglobally) asymptotically stable to the same constant state equilibrium point, $X$, of the system.

Proof. The proof of this theorem is immediate upon realizing that, under the hypothesis on the average control input, $u_{\mathrm{av}}$, the previous theorem establishes that a sliding regime exists on the manifold $e=0$. Under the invariance conditions, $e=0, \dot{e}=0$, which characterize ideal sliding motions [61], the corresponding equivalent control, $u_{\mathrm{eq}}$, associated with the system satisfies $u_{\mathrm{eq}}(t)=u_{\mathrm{av}}(t)$. The ideal sliding dynamics is then represented by

$$
\begin{aligned}
\dot{x} & =f(x)+u_{\mathrm{av}} g(x), \\
y & =h(x), \\
u_{\mathrm{av}}(y, \zeta) & =-\kappa(y, \zeta, X), \\
\dot{\zeta} & =\varphi(y, \zeta, X),
\end{aligned}
$$

which is assumed to exhibit the desired constant state $X$ as a locally (globally, semiglobally) asymptotically stable equilibrium point.

Remark A.3. Note that the $\Sigma-\Delta$-modulator state, $e$, can be initialized at the value $e\left(t_{0}\right)=0$. This implies that the induced sliding regime exists uniformly for all times after $t_{0}$. Hence, no reaching time of the sliding surface, $e=0$, is required.

\section{Conflict of Interests}

The authors declare that the research was conducted in the absence of any commercial, financial, or personal relationships that could be construed as a potential conflict of interests.

\section{Acknowledgments}

The authors wish to thank the anonymous reviewers for their helpful comments and critical review. Likewise, the authors would like to thank M. Antonio-Cruz for her technical support in this research. R. Silva-Ortigoza, M. Marcelino-Aranda, and H. Taud acknowledge financial support from the Secretaría de Investigación y Posgrado del Instituto Politécnico Nacional (SIP-IPN), SNI-Mexico, and the IPN programs EDI and COFAA. Also, M. MarcelinoAranda acknowledges financial support from IPN through the Proyectos de Investigación en Apoyo a la Consolidación de Profesores SNI del IPN. The work of D. Muñoz-Carrillo was supported by CONACYT-Mexico scholarship. Finally, Marianela, Rhomy, and Rhena deserve a special mention from R. Silva-Ortigoza for their constant immense moral support.

\section{References}

[1] S. V. Emelyanov, Variable Structure Control Systems, Nauka, Moscow, Russia, 1967.

[2] V. I. Utkin, Sliding Modes and their Applications in Variable Structure Systems, Mir Publishers, Moscow, Russia, 1978.

[3] V. I. Utkin, Sliding Modes in Control and Optimization, Communications and Control Engineering Series, Springer, Berlin, Germany, 1992.

[4] V. I. Utkin, J. Guldner, and J. Shi, Sliding Mode Control in Electromechanical Systems, Taylor \& Francis, London, UK, 1999.

[5] C. Edwards and S. K. Spurgeon, Sliding Mode Control: Theory and Applications, Taylor \& Francis, London, UK, 1998. 
[6] J. Slotine and W. Li, Applied Nonlinear Control, Prentice-Hall, Englewood Cliffs, NJ, USA, 1991.

[7] S. Sastry, Nonlinear Systems: Analysis, Stability, and Control, Springer, New York, NY, USA, 1999.

[8] H. G. Kwatny and G. L. Blankenship, Nonlinear Control and Analytical Mechanics: A Computational Approach, Birkhäuser, Boston, Mass, USA, 2000.

[9] S. H. Żak, Systems and Control, Oxford University Press, New York, NY, USA, 2003.

[10] K. D. Young and Ü. Özgüner, Eds., Variable Structure Systems, Sliding Mode and Nonlinear Control, vol. 247 of Lecture Notes in Control and Information Sciences, Springer, London, UK, 1999.

[11] W. Perruquetti and J. P. Barbot, Eds., Sliding Mode Control in Engineering, Marcel Dekker, New York, NY, USA, 2002.

[12] A. Sabanovic, L. M. Fridman, and S. Spurgeon, Variable Structure Systems: From Principles to Implementation, IET Press, London, UK, 2004.

[13] L. Fridman, J. Moreno, and R. Iriarte, Eds., Sliding Modes after the First Decade of the 21st Century: State of the Art, vol. 412 of Lecture Notes in Control and Information Sciences, Springer, Heidelberg, Germany, 2011.

[14] H. R. Karimi, "A sliding mode approach to $H_{\infty}$ synchronization of master-slave time-delays systems with Markovian jumping parameters and nonlinear uncertainties," Journal of the Franklin Institute, vol. 349, no. 4, pp. 1480-1496, 2012.

[15] J. Yu, G. Sun, and H. R. Karimi, "Fault-reconstruction-based cascaded sliding mode observers for descriptor linear systems," Mathematical Problems in Engineering, vol. 2012, Article ID 623426, 20 pages, 2012.

[16] B. Wang, P. Shi, and H. R. Karimi, "Fuzzy sliding mode control design for a class of disturbed systems," Journal of the Franklin Institute, vol. 351, no. 7, pp. 3593-3609, 2014.

[17] H. Li, J. Yu, C. Hilton, and H. Liu, "Adaptive sliding-mode control for nonlinear active suspension vehicle systems using TS fuzzy approach," IEEE Transactions on Industrial Electronics, vol. 60, no. 8, pp. 3328-3338, 2013.

[18] H. Li, X. Jing, and H. R. Karimi, "Output-feedback-based $H_{\infty}$ control for vehicle suspension systems with control delay," IEEE Transactions on Industrial Electronics, vol. 61, no. 1, pp. 436-446, 2014.

[19] H. Li, X. Jing, H.-K. Lam, and P. Shi, "Fuzzy sampled-data control for uncertain vehicle suspension systems," IEEE Transactions on Cybernetics, vol. 44, no. 7, pp. 1111-1126, 2014.

[20] R. Silva-Ortigoza, V. Hernández-Guzmán, M. Antonio-Cruz, and D. Muñoz-Carrillo, "DC/DC Buck power converter as a smooth starter for a DC motor based on a hierarchical control," IEEE Transactions on Power Electronics, vol. 30, no. 2, pp. 10761084, 2015.

[21] V. M. Hernández-Guzmán, R. Silva-Ortigoza, and D. MuñozCarrillo, "Velocity control of a brushed DC-motor driven by a DC to DC Buck power converter," International Journal of Innovative Computing, Information and Control, vol. 11, no. 2, 13 pages, 2015.

[22] H. Sira-Ramírez and R. Silva-Ortigoza, "Sliding mode $\Sigma-\Delta$ modulation control of the Boost converter," Asian Journal of Control, vol. 7, no. 4, pp. 349-355, 2005.

[23] H. Sira-Ramírez and R. Silva-Ortigoza, Control Design Techniques in Power Electronics Devices, Springer, London, UK, 2006.

[24] P. T. Krein, J. Bentsman, R. M. Bass, and B. C. Lesieutre, "On the use of averaging for the analysis of power electronic systems,"
IEEE Transactions on Power Electronics, vol. 5, no. 2, pp. 182190, 1990.

[25] R. Steele, Delta Modulation Systems, Pentech Press, London, UK, 1975.

[26] S. R. Norsworthy, R. Schreier, and G. C. Temes, Eds., DeltaSigma Data Converters: Theory, Design, and Simulation, IEEE Press-Wiley, Piscataway, NJ, USA, 1997.

[27] M. He and J. Xu, "Nonlinear PID in digital controlled buck converters," in Proceedings of the 22nd Annual IEEE Applied Power Electronics Conference and Exposition (APEC '07), pp. 1461-1465, Anaheim, Calif, USA, March 2007.

[28] E. W. Zurita-Bustamante, J. Linares-Flores, E. GuzmánRamírez, and H. Sira-Ramírez, "A comparison between the GPI and PID controllers for the stabilization of a dc-dc "buck" converter: a field programmable gate array implementation," IEEE Transactions on Industrial Electronics, vol. 58, no. 11, pp. 5251-5262, 2011.

[29] J. Linares-Flores, Control suave de velocidad de motores de CD mediante convertidores de potencia CD/CD [Ph.D. thesis], Sección de Mecatrónica del Departamento de Ingeniería Eléctrica del CINVESTAV-IPN, Mexico City, Mexico, 2006.

[30] F. Antritter, P. Maurer, and J. Reger, "Flatness based control of a buck-converter driven DC motor," in Proceedings of the 4th IFAC Symposium on Mechatronic Systems (MX '06), pp. 36-41, Ruprecht-Karls-University, September 2006.

[31] H. El Fadil and F. Giri, "Accounting of Dc-Dc power converter dynamics in DC motor velocity adaptive control," in Proceedings of the IEEE International Conference on Control Applications (CCA '06), pp. 3157-3162, Munich, Germany, October 2006.

[32] J. Linares-Flores, H. Sira-Ramírez, J. Reger, and R. SilvaOrtigoza, "An exact tracking error dynamics passive output feedback controller for a Buck-Boost-converter driven DC motor," in Proceedings of the 10th IEEE International Power Electronics Congress (CIEP '06), pp. 1-5, Puebla, Mexico, October 2006.

[33] J. Linares-Flores, J. Reger, and H. Sira-Ramirez, "Load torque estimation and passivity-based control of a boost-converter/ DC-motor combination," IEEE Transactions on Control Systems Technology, vol. 18, no. 6, pp. 1398-1405, 2010.

[34] R. Silva-Ortigoza, C. Márquez-Sánchez, F. Carrizosa-Corral, M. Antonio-Cruz, J. M. Alba-Martínez, and G. Saldaña-González, "Hierarchical velocity control based on differential flatness for a DC/DC Buck converter-DC motor system," Mathematical Problems in Engineering, vol. 2014, Article ID 912815, 12 pages, 2014.

[35] H. El Fadil, F. Giri, F.-Z. Chaoui, and O. El Magueri, "Accounting for input limitation in the control of Buck power converters," IEEE Transactions on Circuits and Systems I: Regular Papers, vol. 56, no. 6, pp. 1260-1271, 2009.

[36] J. Linares-Flores, H. Sira-Ramírez, E. F. Cuevas-López, and M. A. Contreras-Ordaz, "Sensorless passivity based control of a DC motor via a solar powered sepic converter-full bridge combination," Journal of Power Electronics, vol. 11, no. 5, pp. 743750, 2011.

[37] J. Lira, N. Visairo, C. Nunez, A. Ramirez, and H. Sira-Ramrez, "A robust nonlinear control scheme for a sag compensator active multilevel rectifier without sag detection algorithm," IEEE Transactions on Power Electronics, vol. 27, no. 8, pp. 3576-3583, 2012.

[38] V. M. Hernández-Guzmán, R. Silva-Ortigoza, and R. V. Carrillo-Serrano, Control Automático: Teoría de Diseño, Construcción de Prototipos, Modelado, Identificación y Pruebas 
Experimentales, Colección CIDETEC-IPN, Mexico City, Mexico, 2013, http://www.controlautomatico.com.mx/.

[39] R. Silva-Ortigoza, C. Márquez-Sánchez, F. Carrizosa-Corral et al., "Obstacle avoidance task for a wheeled mobile robot-a Matlab-Simulink-based didactic application," in MATLAB: Applications for the Practical Engineer, K. Bennett, Ed., pp. 79-102, InTech Europe, Rijeka, Croatia, 2014, http://www.intechopen.com/books/matlab-applications-for-the-practical-engineer.

[40] G. Capponi, P. Livreri, G. di Blasi, and F. Marino, "Digital power conversion system based on a sigma-delta modulator linear model," in Proceedings of the IEEE PES Power Systems Conference and Exposition, pp. 1467-1469, New York, NY, USA, October 2004.

[41] M. Oliver-Salazar and H. Sira-Ramírez, "Semi-global stabilization for the Buck-Buck converter via exact tracking error dynamics passive output feedback," in Proceedings of the 8th International Conference on Electrical Engineering, Computing Science and Automatic Control (CCE '11), pp. 1-6, Mérida, México, October 2011.

[42] H. Sira-Ramírez, A. Luviano-Juárez, and J. Cortés-Romero, "Robust input-output sliding mode control of the buck converter," Control Engineering Practice, vol. 21, no. 5, pp. 671-678, 2013.

[43] J. Linares-Flores and H. Sira-Ramírez, "A smooth starter for a DC machine: a flatness based approach," in Proceedings of the 1st International Conference on Electrical and Electronics Engineering (ICEEE '04), pp. 589-594, Acapulco, México, September 2004.

[44] J. Linares-Flores and H. Sira-Ramírez, "Sliding Mode-Delta modulation GPI control of a DC motor through a Buck converter," in Proceedings of the 2nd IFAC Symposium on System, Structure and Control, pp. 405-410, Oaxaca, México, December 2004.

[45] J. Linares-Flores and H. Sira-Ramírez, "DC motor velocity control through a DC-to-DC power converter," in Proceedings of the 43rd IEEE Conference on Decision and Control (CDC '04), pp. 5297-5302, Paradise Island, The Bahamas, December 2004.

[46] R. Silva-Ortigoza, J. R. García-Sánchez, J. M. Alba-Martínez et al., "Two-Stage control design of a Buck converter/DC motor system without velocity measurements via a $\Sigma-\Delta$-modulator," Mathematical Problems in Engineering, vol. 2013, Article ID 929316, 11 pages, 2013.

[47] R. Silva-Ortigoza and H. Sira-Ramírez, "Control of a parallel resonant inverter," in Proceedings of the 43rd IEEE Conference on Decision and Control (CDC'04), pp. 5303-5307, Paradise Island, The Bahamas, December 2004.

[48] C. García-Rodríguez, J. A. Cortés-Romero, and H. SiraRamírez, "Algebraic identification and discontinuous control for trajectory tracking in a perturbed 1-DOF suspension system," IEEE Transactions on Industrial Electronics, vol. 56, no. 9, pp. 3665-3674, 2009.

[49] E. Dallago, A. Danioni, M. Passoni, and G. Venchi, "Comparison between PWM and sigma-delta modulation in a power factor correction system," in Proceedings of the IEEE 33rd Annual Power Electronics Specialists Conference (PESC '02), pp. 1027-1030, Piscataway, NJ, USA, June 2002.

[50] S. K. Dunlap and T. S. Fiez, "A noise-shaped switching power supply using a delta-sigma modulator," IEEE Transactions on Circuits and Systems I: Regular Papers, vol. 51, no. 6, pp. 10511061, 2004.
[51] A. Hirota, S. Nagai, B. Saha, and M. Nakaoka, "Fundamental study of a simple control ac-ac converter introducing deltasigma modulation approach," in Proceedings of the IEEE International Conference on Industrial Technology (ICIT '08), pp. 1-5, Chengdu, China, April 2008.

[52] S. Orcioni, R. D. D’Aparo, G. Crostella, D. Nicoletti, and M. Conti, "Dynamic oversampling ratio sigma-delta modulation for the control of switching power converter," in Proceedings of the IEEE International Symposium of Circuits and Systems (ISCAS '11), pp. 2781-2784, Rio de Janeiro, Brazil, May 2011.

[53] M. Fliess, J. Lévine, P. Martin, and P. Rouchon, "Flatness and defect of non-linear systems: introductory theory and examples," International Journal of Control, vol. 61, no. 6, pp. 13271361, 1995.

[54] M. H. Rashid, Power Electronics: Circuits, Devices and Applications, Prentice-Hall, 3rd edition, 2003.

[55] W. Shockley, "The theory of $p-n$ junctions in semiconductors and $p-n$ junction Transistors," Bell System Technical Journal, vol. 28, no. 3, pp. 435-489, 1949.

[56] J. J. Ebers and J. L. Moll, "Large-signal behavior of junction transistors," Proceedings of the IRE, vol. 42, no. 12, pp. 1761-1772, 1954.

[57] H. Sira-Ramírez and S. K. Agrawal, Differentially Flat Systems, Marcel Dekker, New York, NY, USA, 2004.

[58] D. G. Holmes and T. A. Lipo, Pulse Width Modulation for Power Converters: Principles and Practice, IEEE Press-Willey, Piscataway, NJ, USA, 2003.

[59] J.-P. Vilain and C. Lesbroussart, "Delta-sigma modulation," in Power Electronic Converters: PWM Strategies and Current Control Techniques, E. Monmasson, Ed., pp. 119-140, WileyISTE, New York, NY, USA, 2011.

[60] R. C. Dorf and R. H. Bishop, Modern Control Systems, PrenticeHall, 12th edition, 2011.

[61] H. Sira-Ramirez, "Differential geometric methods in variablestructure control," International Journal of Control, vol. 48, no. 4, pp. 1359-1390, 1988. 


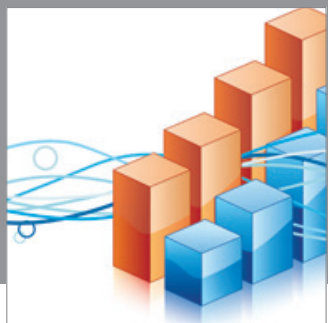

Advances in

Operations Research

mansans

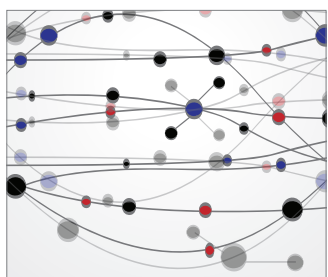

The Scientific World Journal
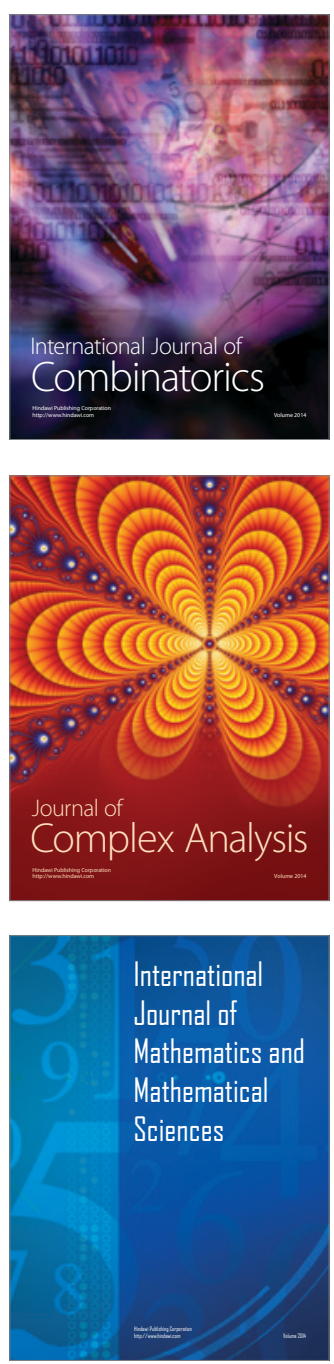
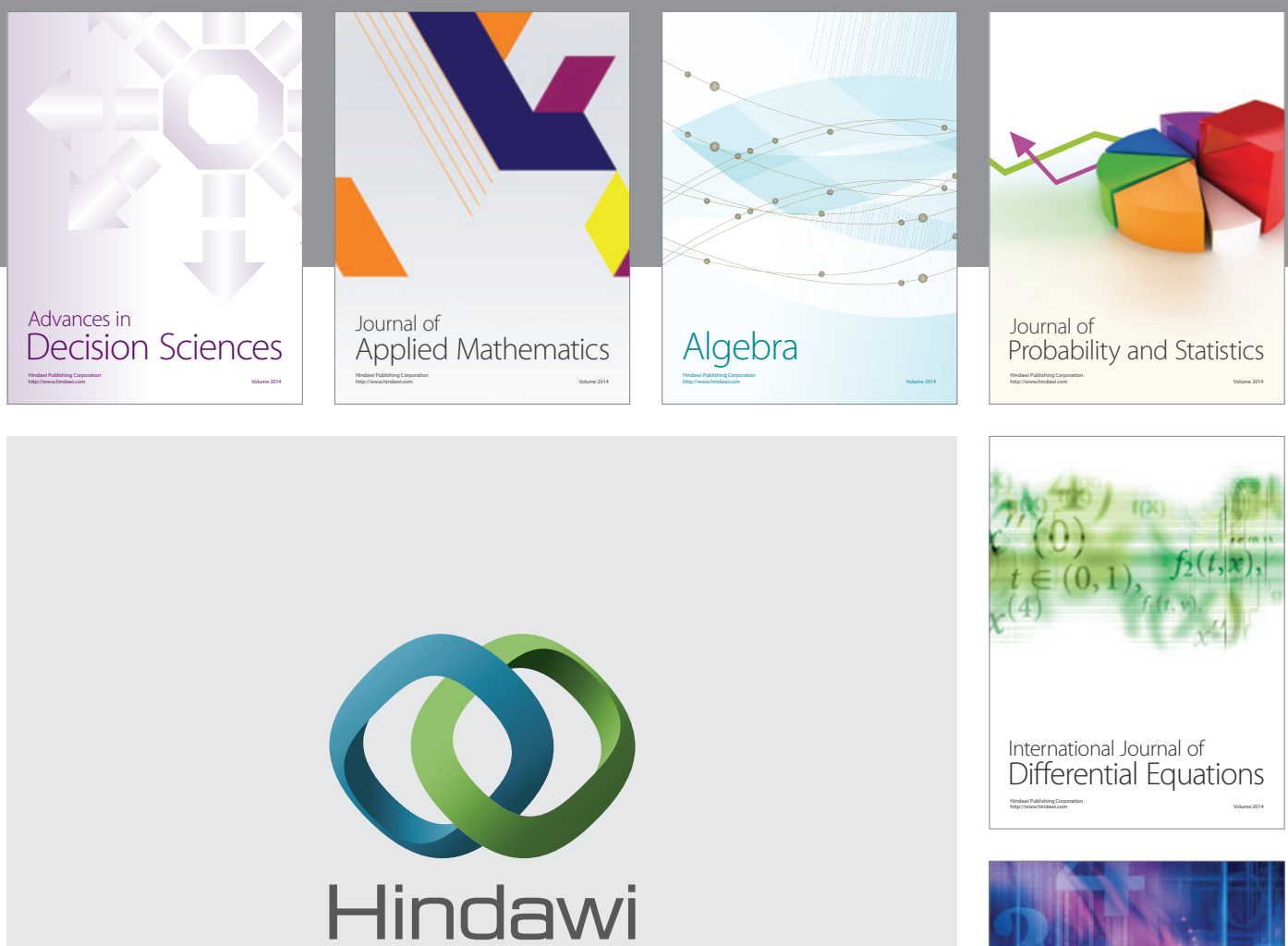

Submit your manuscripts at http://www.hindawi.com
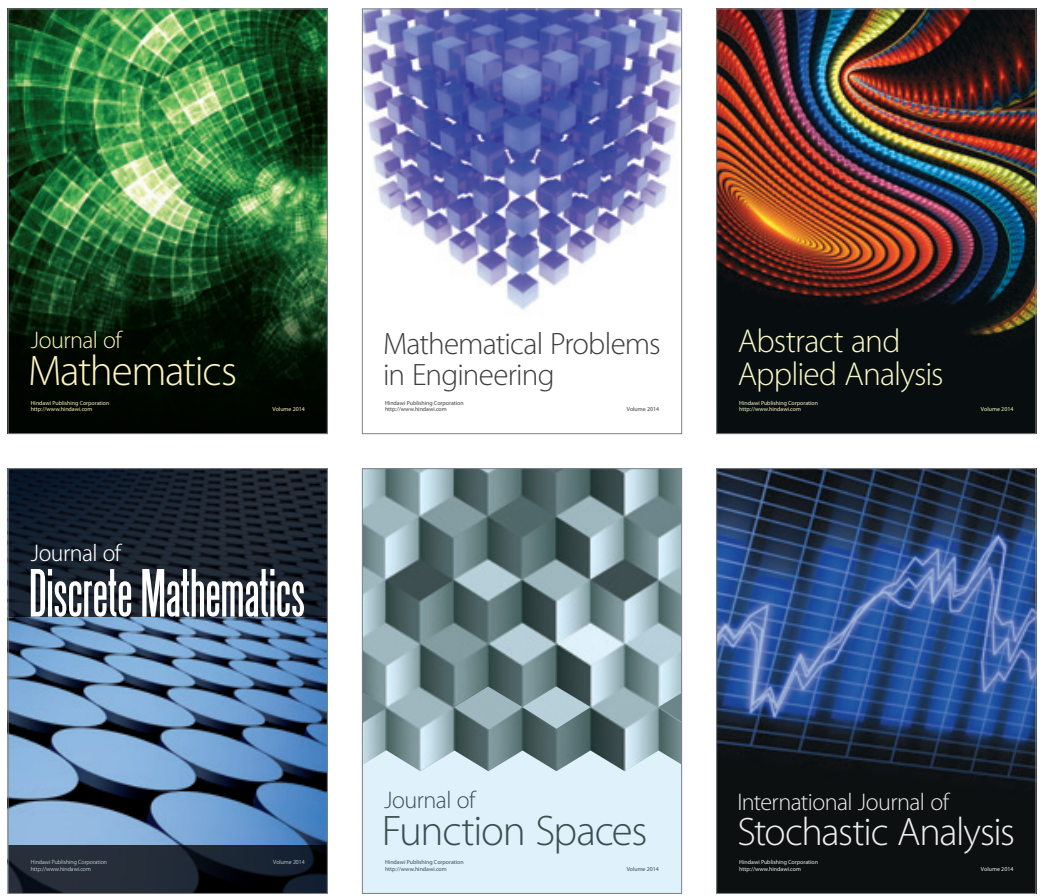

Journal of

Function Spaces

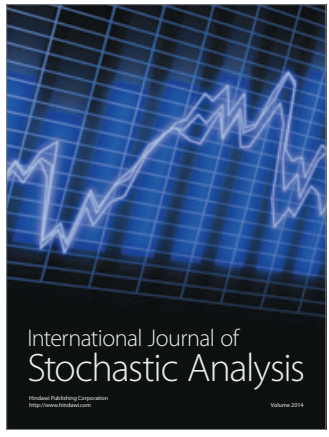

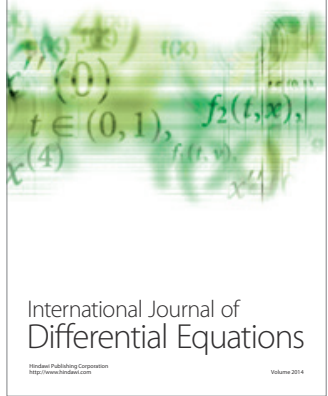
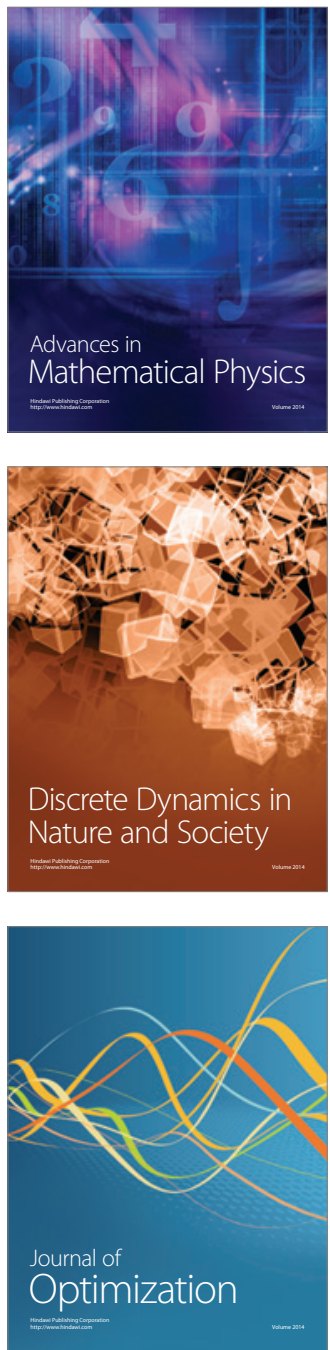